\title{
Principes de la lutte microbiologique en agriculture
}

\author{
par B. HURPIN
}

institut National de la Recherche Agronomique, La Minière, F - 78 -Versailles

Station de Recherches de Lutte Biologique et de Biocanotique

\begin{abstract}
Résumé
L'expérience acquise après plus d'une décennie de développement des recherches en pathologie des insectes permet de tenter d'établir un premier bilan et de dégager quelques principes à retenir pour l'application de la lutte microbiologique en agriculture. Ces principes découlent, d'une part de nos connaissances sur les propriétés pathologiques et épizootiolcziques des germes considérés, d'autre part des caractéristiques écologiques des milieux concernés ainsi que des impératifs agronomiques et économiques.
\end{abstract}

\section{Bases microbiologiques.}

C'est dans l'isolement et la caractérisation des différentes catégories de pathogènes que les recherches ont été les plus poussées. Elles ont abouti à une liste de plus d'un millier d'espèces appartenant à tous les groupes: bactéries, rickettsies, virus, protozoaires, champignons, en négligeant les nématodes, parmi lesquelles seules deux bactéries, trois champignons et quelques virus ont fait l'objet d'expérimentations.

Les propriétés microbiologiques et les potentialités de ces 5 types de germe sont rappelées en insistant sur les aspects intéressant la lutte microbiologique: virulence, spécificité, rémanence, facultés de conservation, possibilité de multiplication industrielle.

\section{Bases pathologiques.}

Le recours à l'arme microbiologique en défense des cultures est en fonction des données acquises sur les processus pathologiques déterminant l'évolution des maladies de l'état enzootique vers 
l'état épizootique, après intervention ou non de l'Homme. Ces phénomènes sont liés à la fois à l'agressivité du germe et à la réceptivité de l'hôte, mais aussi à l'action du milieu. Il est ainsi brièvement discuté du rôle respectif de la virulence des souches, de l'origine du pathogène (endémique ou introduit), de la biomasse des microorgan:smes d'une part, de la sensibilité de l'insecte d'autre part, qui peut dépendre de son stade, de sa race, de la phase gradologique de la population ou de l'état physiologique provoqué par des déséquilibres nutritionnels, des intoxications ou des troubles pathologiques, infections chroniques ou latentes, maladies à enchaînements.

Dans cette «balance » entre le germe et l'hôte, les facteurs $\mathrm{du}$ milieu ont une influence à la fois sur les deux populations antagonistes considérées isolément et sur leur interaction selon des phénomènes de «stress » dans lesquels les facteurs prédisposants concernent l'hôte alors que les facteurs activateurs agissent sur le microorganisme.

\section{Bases écologiques.}

L'idéal de la lutte microbiologique est d'aboutir à l'introduction dans un écosystème d'un agent de régulation permanente du niveau de population du ravageur au-dessous du seuil de nuisibilité pour la culture considérée. Ce caractère de prévention à long terme implique de tenir compte non seulement de l'insecte à combattre et du germe à utiliser mais aussi de l'environnement dans lequel est effectuée la dispersion du pathogène. L'unité de surface pour les applications doit être représentative de cet environnement et constituer un écosystème autonome, elle est donc d'importance très variable selon la formation végétale considérée: forêt, culture permanente, semi-permanente ou annuelle et selon la nature géographique du milieu.

Dans ce contexte, les stations refuges ont une place privilégiée et, en milieu cultivé, il ne faut pas négliger l'action des façons culturales et l'influence des rotations sur la survie de l'hôte et du pathogène. La persistance endémique de celui-ci est liée, en effet, au maintien d'une population minimum de sorte que, dans l'appréciation des résultats d'une application, la morbidité a plus d'importance que la mortalité.

Le pathogène introduit entre en concurrence avec les autres agents biotiques de régulation de la population-hôte (entomophages, autres maladies), aussi son application doit être faite lorsque la biolog:e de l'espèce, le stade d'évolution du ravageur, l'état gradologique de la population permettent d'espérer qu'il constituera un des « facteurs clés » dans la dynamique de cette population. 
Le traitement généralisé par un microorganisme entraîne une certaine pollution du milieu qu'il est préférable d'essayer d'éviter en ayant recours à des applications localisées.

\section{Bases agronomiques.}

Les connaissances du microbiologiste, les conditions du pathologiste et le point de vue de l'écologiste ne sont pas toujours en accord avec les besoins de l'agronome. Ainsi la sélectivité de l'arme microbiologique amène le plus souvent à inclure la préparation biologique dans un programme de lutte intégrée; l'action épizootique à long terme est parfois incompatible avec la sauvegarde de la récolte, soit quantitativement en fonction du taux minimum de survie du ravageur et du seuil de tolérance de la culture, soit qualitativement en fonction des normes de commercialisation.

Le type de culture est le facteur déterminant pour le choix d'une technique de lutte. La forêt constitue le milieu le plus favorable à la lutte microbiologique proprement dite, alors que dans les cultures annuelles, il n'est possible actuellement que de recourir à des traitements phytosanitaires sélectifs, à l'aide par exemple de Bacillus thuringiensis ou de certains virus.

\section{Summary}

The experience gained after more than ten years of research in insect pathology makes it possible to survey the results, and to establish some principles for applied microbial control in agriculture. These principles should be based on our knowledge regarding the pathology and epizootiological properties of the considered pathogens and the ecological characteristics of the studied environment as well ; in addition, it should rely on agronomic and economic requirements.

\section{Microbial basis.}

Research has been concentrated on the isolation and characterization of the various types of pathogens. It has permitted to list more than a thousand species belonging to all kinds of groups: Bacteria, Rickettsia, Viruses, Protozoa, Fungi, among which only two bacteria, three fungi and some viruses have been tested. The microbial characteristics and potentialities of these 5 categories of pathogens are recalled, with special consideration of their microbial control properties: virulence, specificity, remanence, conservation power and possible industrial production. 


\section{Pathological basis.}

The chances to succeed in crop protection by biological means depends on the data available on the pathological processes determining the evolution of diseases from an enzootic state to an epizootic one, whether man has interfered or not.

These phenomena are linked to the pathogen's agressiveness, and to the host's receptivity as well and underlie the environmental effect. The proper roles of the strains virulence, the origin of the pathogen (endemic or introduced), of the importance of the biomass of the microorganisms, compared to the insect susceptibility which can depend on its developmental stage, its strain, the «gradological» state of population determined by nutritional unbalance, intoxication or pathological disorders, chronic or latent infections, sequence diseases, are briefly discussed.

In this balance between the pathogen and the host, the environmental factors have an effect both on the antagonistic populations considered separately and on their interacting according to stress phenomena in which the predisposing factors affect the host while the activating factors acts on the micro-organism.

\section{Ecological basis.}

In microbial control, the ideal is to succeed in introducing into an ecosystem a permanent regulating agent keeping the pest population level under the threshold injurious for the crop. For this long-term forecasting it is the insect to control and the pathogen to use that have to be considered in connection with the environment in which the latter is spread. The unit of the area unit retained for the application should be representative for the environment concerned and represent a self-regulating ecosystem. Therefore, the size of the surface is largely depending on the plant community considered : forest, permanent crop, semi-permanent or annual crop, whereby the character of the environment has also to be considered.

In this connection, the so called «Stations refuges » have a privileged position, and in areas with cropping the effects of cultural practices and crop rotations on the survival of both the host and the pathogen should be considered. The chances of endemic persistence of the latter are linked with the possibilities to maintain the population at a minimal level. Therefore, in estimating the results of an application, the degree of morbidity is more important than the mortality.

The introduced pathogen has to compete with other biotic agents regulating the host population (entomophagous insects, other diseases) and the introduction should thus be done according to the most convenient time especially in respect to biology of the 
species, the stage of evolution of the pest and the « gradological » state of the population in order to ensure that it acts as a « key factor».

The general application of a microorganism induces a certain pollution of the environment which should better be avoided by local introduction.

\section{Agronomic basis.}

The microbiologist's knowledge, the pathologist's conditions and the ecologist's point of view are not necessarily in agreement with the agronomist's requirements. The selectivity of the microbial means most often brings the necessity to apply it in the frame of an integrated control program; the long term epizootic action is sometimes incompatible with a safe cropping as either the quantity may be affected by the remained minimum level of pests exceeding tolerated thresholds, or there are qualitative involvements with respect to commercial standards. The type of crop is decisive for the choice of a control technique. Forests represent the most favourable environment for microbial control methods whereas annual crops can for the moment only be treated biologically with selective compounds like Bacillus thuringiensis and some viruses.

Louis Pasteur (1874), en conclusion de ses travaux sur les maladies du ver à soie et devant les problèmes posés par l'invasion du Phylloxera, suggéra les possibilités que l'emploi de certaines maladies pouvait offrir pour lutter contre les insectes nuisibles à l'agriculture. Simultanément, Le Conte (1872), aux Etats-Unis, formula la même proposition. Mais ce n'est que quelques années plus tard que les recherches furent entreprises par quelques précurseurs, tels Metchnikov, Krassil'schik, Paillot, d'Hérelle, pour mettre en application cette idée et déterminer l'usage susceptible d'être fait de bactéries, de champignons ou de virus pour la protection des cultures. Les résultats de ces premières applications de genres entomopathogènes furent très variables, et dans l'ensemble les échecs estompèrent les rares succès, de sorte qu'un discrédit tenace fut porté à cette méthode.

Ce sont les travaux et les écrits de Steinhaus $(1946,1949)$ et des chercheurs californiens, appuyés sur les résultats démonstratifs d'application dans la pratique agricole (80.000 ha traités de 1939 à 1952 par les services du Ministère de l'Agriculture, sans compter les traitements privés) de la bactérie Bacillus popilliae Dutky pour faire face à l'invasion du nord-est des Etats-Unis par le Hanneton japonais, qui relancèrent l'idée de la lutte microbiologique contre les ravageurs des cultures, à la fin de la seconde guerre mondiale.

A la même époque, les insecticides organiques de synthèse furent découverts, puis 
vite vulgarisés et employés sur des superficies considérables contre des espèces de plus en plus nombreuses du fait de la diversification des produits : chlorés, phosphorés, carbamates, systémiques, etc. Ces produits, par leur grande toxicité pour les insectes, leur rapidité d'action, leur facilité de production, de conservation et d'utilisation, leur polyvalence d'activité et aussi la diversité de leurs modes d'action, apportèrent relativement facilement des solutions, que certains estimèrent définitives, à la plupart des problèmes posés par les insectes en défense des cultures.

Mais ces produits ne tardèrent pas à faire preuve d'un certain nombre d'inconvénients, sur lesquels il est inutile d'insister, car l'attention des spécialistes et du public a été maintes fois attirée sur ces aspects négatifs et ces dangers des insecticides chimiques: destruction des insectes utiles (entomophages, pollinisateurs), perturbations des biocénoses pouvant entraîner, par exemple, des substitutions de ravageurs, apparition de races résistantes nécessitant des doses de plus en plus élevées ou des produits plus toxiques accroissant les dangers pour l'homme et les vertébrés, sans oublier les risques de phytotoxicité et, pour certains de ces produits, le passage et l'accumulation dans les chaînes trophiques, dont les conséquences directes ou indirectes ne sont pas toujours bien établies et sont liées aux doses de résidus admissibles.

La prise de conscience de ces dangers a déterminé un nouvel essor des recherches en lutte biologique, et en particulier en pathologie des insectes, dans de nombreux pays du monde : Etats-Unis, Canada, U.R.S.S., Allemagne fédérale, Pologne, Tchécoslovaquie, afin de mettre au point des méthodes plus rationnelles, car biologiques, pour limiter les dégâts provoqués par les insectes à des niveaux supportables économiquement.

En France, de telles recherches ont été développées par l'Institut national de la recherche agronomique, qui a créé deux laboratoires: la Station de recherches cytopathologiques de Saint-Christol-lès-Alès, dirigée par C. Vago, pour la diagnose et l'étude pathologique des germes, spécialement des virus, susceptibles d'être utilisés, et la Station de recherches de biocœnotique et de lutte biologique de La Minière, dirigée par P. Grison, pour la définition des conditions écologiques favorisant les épizooties naturelles ou provoquées, en liaison avec des instituts spécialisés tels que l'Institut Pasteur de Paris. La création, en 1966, d'un Comité scientifique de lutte biologique au sein de la D.G.R.S.T. a stimulé les travaux en ce domaine et donné les moyens d'étendre et de concrétiser les investigations.

L'expérience acquise après douze à quinze années, tant en France qu'à l'étranger, permet de tenter de dresser un premier bilan et de dégager les principes retenus ou à retenir pour la mise en œuvre de la lutte microbiologique en agriculture.

Ces principes sont fondés d'une part sur nos connaissances des propriétés pathologiques et épizootiologiques des germes entomopathogènes, d'autre part sur les caractéristiques écologiques des milieux considérés ainsi que sur les impératifs agronomiques et économiques. 


\section{PROPRIETES DES GERMES ENTOMOPATHOGENES}

\section{A RETENIR POUR LES APPLICATIONS}

La plus grande partie des efforts des spécialistes, jusqu'à présent, a été consacrée à l'isolement, à l'identification et à l'examen des processus pathologiques des microorganismes observés chez les insectes malades dans la nature ou dans les élevages. Il a été ainsi dressé une liste, qui s'allonge constamment, des agents pathogènes pour les ravageurs des cultures ou des forêts. Cette liste comporte maintenant plus d'un millier d'espèces appartenant à tous les groupes: bactéries, rickettsies, virus, protozoaires, champignons, pour ne pas parler des nématodes. Ces grandes catégories ont des propriétés communes qui ont déjà fait l'objet de mises au point (Cameron, 1967 ; Heimpel, 1965 ; Hurpin, 1966 ; Tanada, 1961 ; Vago, 1966 ; Weiser, 1962).

Parmi ces propriétés, pour la protection des plantes, deux nous paraissent primordiales, par opposition avec les défauts de la plupart des organiques de synthèse :

- la spécificité, qui correspond à une des principales qualités de la lutte biologique en général, avec pour corollaire l'innocuité à l'égard de l'homme et des vertébrés ;

- la rémanence, non pas par contamination des chaînes trophiques ou pollution du milieu, mais par création de foyers épizootiques durables.

En outre, ainsi que la plupart des auteurs cités l'ont souligné également, il y a lieu de tenir compte, pour le choix d'un pathogène, d'autres critères tels que ses possibilités de multiplication et de production dans des conditions économiquement et techniquement satisfaisantes, les facultés de conservation avant l'emploi et aussi dans le milieu traité des préparations ainsi obtenues, une résistance suffisante aux facteurs d'agression physicochimiques liés au climat ou au sol par exemple, sans négliger évidemment la virulence des espèces en cause et son maintien dans le temps, et la possibilité de sélection naturelle ou artificielle de souches plus actives ou mieux adaptées. On doit se soucier aussi de l'éventualité d'augmentation de la résistance de l'insecte par sélection ou tout autre processus.

C'est en fonction de tels critères que la sélection de quelques espèces seulement a été opérée ces dernières années parmi les centaines d'espèces répertoriées. Ce qui indique tout le travail qui reste à accomplir pour éprouver les potentialités de beaucoup d'autres entomopathogènes, car les micro-organismes choisis pour les essais d'application ne répondent pas toujours à l'ensemble des impératifs que nous venons de rappeler, ainsi que le montrent les exemples suivants.

\section{Les bactéries.}

Elles sont très fréquentes dans les cadavres d'insectes, mais il est souvent difficile d'établir leur rôle, car beaucoup d'entre elles se développent avant ou après la mort sans en être la cause première, selon un phénomène d'enchaînement de maladies, bien étudié par Vago (1956) notamment. Aussi, Bucher (1960) distingue les pathogènes obligatoires du type $B$. thuringiensis ou $B$. popilliae, les pathogènes facultatives telles que 
Serratia marcescens, et les pathogènes potentielles comme les Pseudomonas ou les Streptococcus. Seules, B. thuringiensis et $B$. popilliae, bactéries sporulées pathogènes obligatoires, ont été retenues jusqu'ici pour des traitements phytosanitaires. $B$. thuringiensis peut être cultivée aisément en fermentateur, et être ainsi la base de préparations industrielles fabriquí,es dans plusieurs pays, dont les Etats-Unis, la France, la Roumanie, l'Union sovié.ique, la Yougoslavie, et utilisables contre certaines espèces de Lépidoptères phytophages ou nuisibles aux denrées (tableau I).

Tableau 1. - Espèces sensibles à Bacillus thuringiensis en plein champ

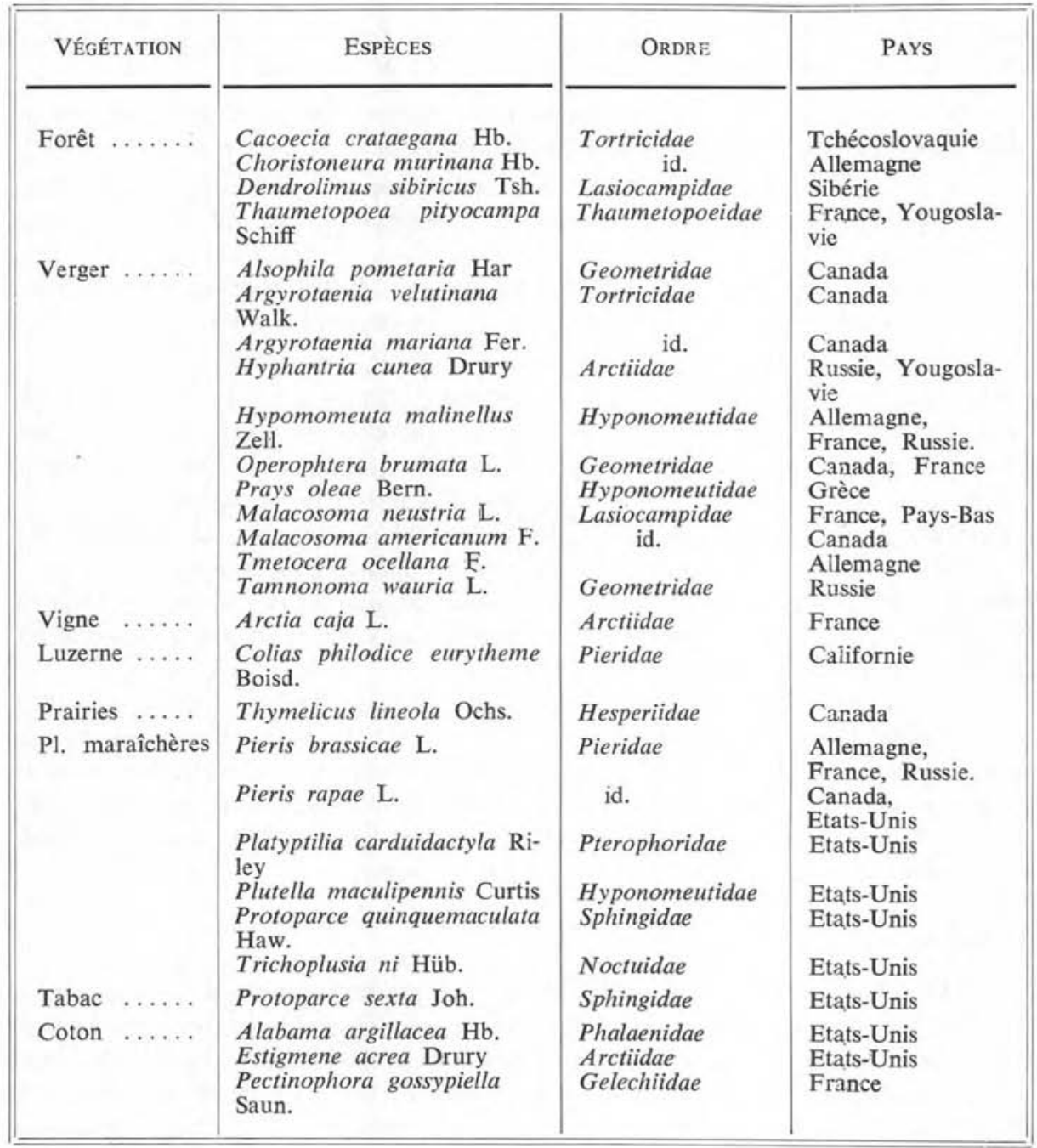


C'est un germe qui se conserve pendant de nombreuses années, dont l'innocuité pour les vertébrés a été vérifiée à maintes reprises, mais dont le mode d'action par intoxication des insectes sensibles, soit par la toxine des cristaux émis en même temps que les spores (Fig. 1), soit, pour certaines souches, par la toxine thermostable soluble dans le milieu de culture, ne permet pas la création de foyers enzootiques ou épizootiques, ce qui est pourtant un des principaux buts recherchés en lutte microbiologique.

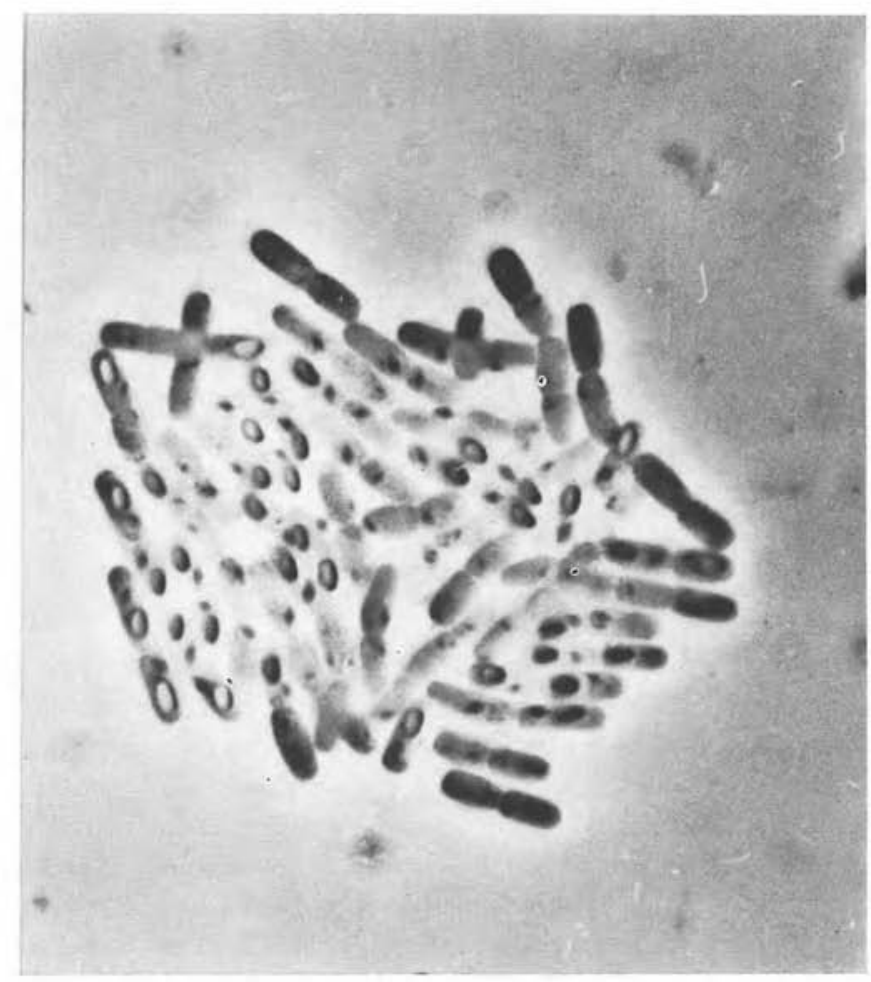

FIG. 1. - Bacillus thuringiensis Berliner. Spores et cristaux dans le sporangium. Contraste de phase $(\times 1.500)$

Dans le cas de $B$. popilliae, également inoffensive pour d'autres espèces que les larves de certains Coléoptères Scarabéides, et dont les spores sont très résistantes (Fig. 2), la pathogénie se traduit par une septicémie aboutissant à la production de plusieurs milliards de spores dans chaque individu.

Ces spores sont libérées dans le sol par la décomposition des cadavres, qui constituent ainsi autant de foyers d'infection. Par contre, en dépit de progrès récents, la multiplication artificielle n'est pas réalisable, et on doit recourir à l'injection individuelle des vers blancs pour la fabrication de poudres de spores. 


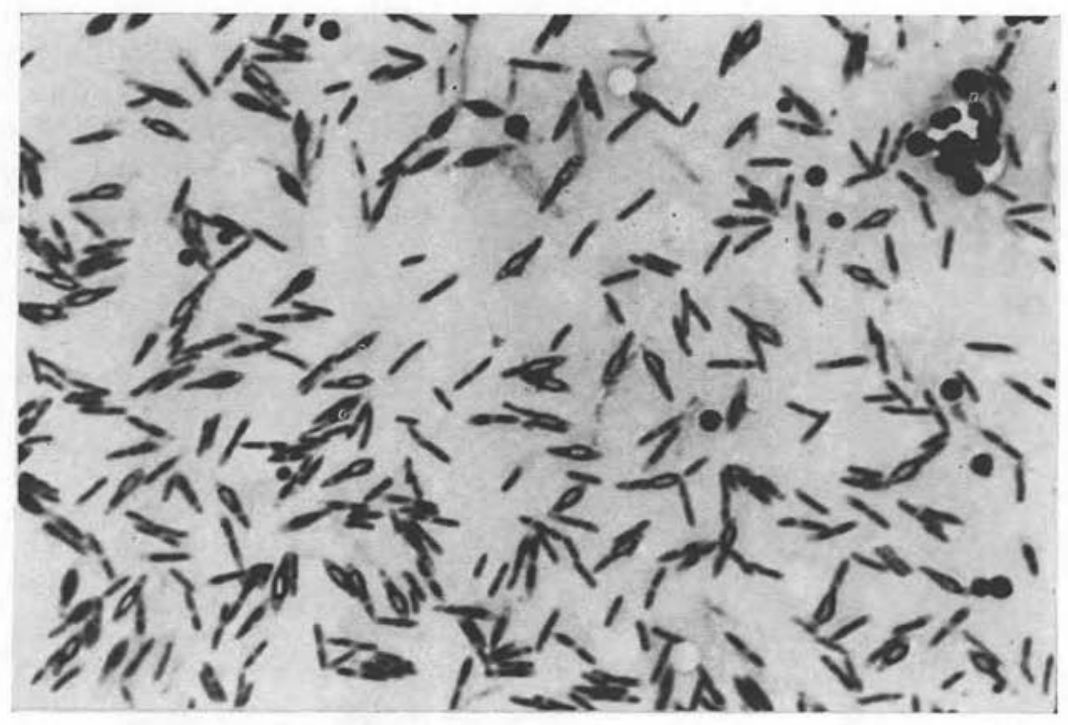

FIG. 2. - Bacillus popilliae «Melolontha». Sporulation. Bleu de Loeffler $(\times 1.000)$

\section{Les virus.}

Ils représentent le groupe d'entomopathogènes de beaucoup le plus important par le nombre d'espèces et aussi par les tentatives d'utilisation. De même que pour les bactéries, ce sont les germes doués de facultés de résistance étendues qui ont fait l'objet des investigations en lutte biologique jusqu'à présent, autrement dit les virus à corps d'inclusion (polyèdres nucléaires ou cytoplasmiques, granules), pathogènes pour de nombreuses espèces de Lépidoptères et certains Hyménoptères (Tenthrèdes). Or, le perfectionnement des techniques (ultracentrifugation, microscopie électronique, etc.), les progrés dans les connaissances et le développement des recherches permettent de fréquentes découvertes de nouveaux virus sans corps d'inclusion, analogues en ce sens aux virus des vertébrés, aussi bien chez des Lépidoptères (Galleria mellonella L., Hyalophora cecropia Meig), des Coléoptères (Oryctes rhinoceros L. ou Melolontha melolontha L.), des Diptères (Tipula paludosa Meig), des Orthoptères (Schistocerca gregaria Försk), que chez les Acariens (Panonychus citri McG.).

En principe, les virus font preuve de spécificité. En fait, pour chaque espèce, il y a lieu de déterminer la gamme d'hôtes dans lesquels elle est susceptible de se multiplier, les essais encore très sporadiques en ce domaine montrant une grande variabilité d'une espèce à l'autre, de sorte qu'on doit penser davantage à un spectre d'activité entomopathogène, plus ou moins large selon les cas, plutôt qu'à une spécificité stricte. Par contre, leur innocuité pour les vertébrés est confirmée à la fois par l'absence du moindre accident pathologique, malgré les épizooties souvent spectaculaires qui inter- 
viennent dans certaines populations d'insectes (Lymantria dispar, Malacosoma neustria, Neodiprion sertifer, par exemple) et amènent la dispersion dans la nature d'une multitude de polyèdres, malgré également les manipulations opérées dans de nombreux laboratoires depuis plus de dix ans, sans précautions spéciales, et aussi par les résultats des essais systématiques entrepris aux Etats-Unis, notamment (Ignoffo et Heimpel, 1965) pour délimiter les effets directs ou indirects des virus entomopathogènes sur souris, cobayes, etc.

Du fait de leur mode d'action, les virus doivent constituer le prototype des agents épizootiques. Ces potentialités de création de foyers d'infection rémanente se trouvent renforcées, dans le cas des virus à corps d'inclusions (Fig. 3), par les facultés de résis-

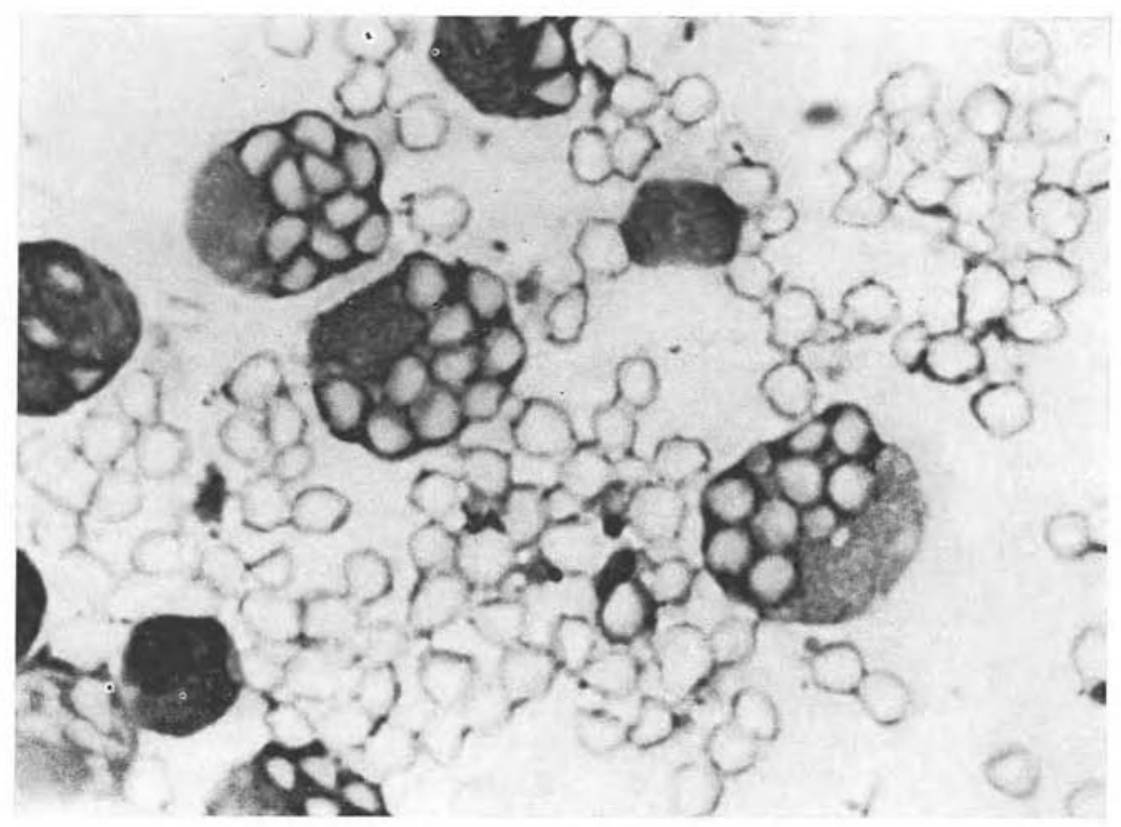

FIG. 3. - Polyedrie nucléaire de Tipula paludosa Meig. Contraste de phase $(\times 1.200)$

tance aux agents climatiques et physiques que leur confère l'enrobage des particules virales dans les polyèdres ou les granules, de sorte qu'on peut envisager la conservation de ces virus dans les milieux où ils ont été dispersés, de la même façon que des spores de bactéries. En outre, cette résistance permet aux corps d'inclusion d'être véhiculés par des insectes détritiphages ou entomophages qui contribuent ainsi à leur dissémination. Ces modalités "exogènes " de maintien et de diffusion dans le milieu considéré peuvent être complétées par des processus intrinsèques propres aux virus, inclus ou libres, assurant la transmission dans une population par l'intermédiaire de l'œuf, par infection de l'ovaire et de l'ovocyte ou, plus souvent, par contamination du chorion. 
Toutefois, les virus, par leur définition même, sont intracellulaires, et la multiplication en milieux artificiels n'est pas possible, tandis que la production sur cultures de tissus d'insectes n'est pas encore réalisable industriellement.

Aussi, la matière active, parfois plusieurs tonnes, nécessaire aux traitements effectués depuis près de vingt ans dans de nombreux pays (tableau 2) a été obtenue par

Tableau 2. - Essais dans la nature d'utilisation avec succès de virus entomopathogènes.

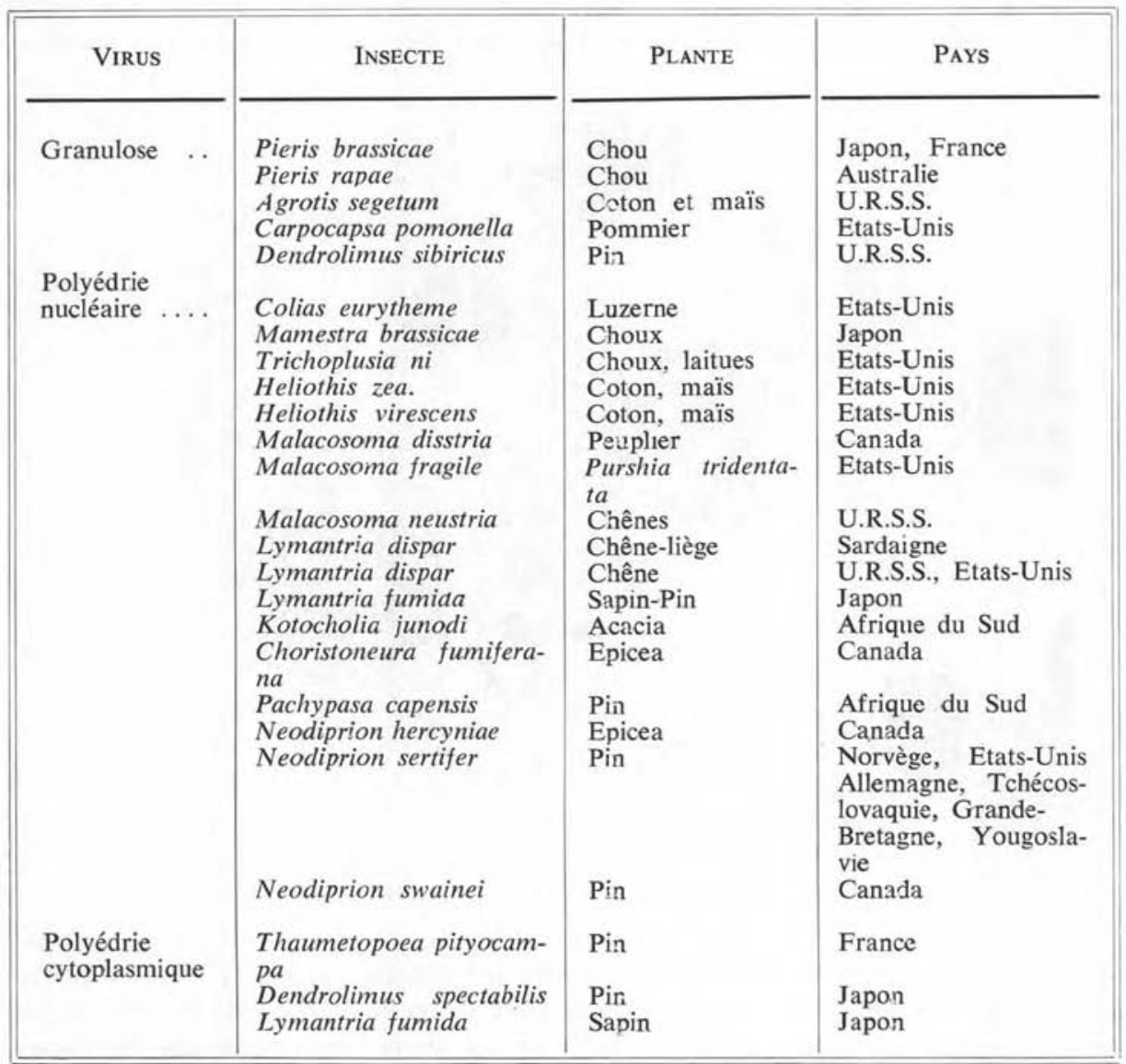

infection d'insectes en élevage. Ce qui représente un handicap sérieux pour la vulgarisation, car la conduite d'un élevage massif d'insectes phytophages suppose des moyens importants et du personnel compétent, et présente le plus souvent un caractère aléatoire. En effet, les connaissances acquises par des élevages à petite échelle se sont révélées à maintes reprises insuffisantes pour mener à bien, sans risques d'incidents 
pathologiques ou physiologiques, des élevages de masses destinés à la production de quantités importantes de virus. Des progrès sensibles ont été enregistrés dans cette voie par la mise au point, pour un nombre de plus en plus grand d'espèces d'insectes, de milieux d'élevages artificiels qui permettent d'uniformiser davantage et de mieux mâ̂triser certains aspects du développement de l'hôte. Ce sont de tels milieux qui sont utilisés aux Etats-Unis pour la multiplication semi-industrielle des virus des Noctuelles, Trichoplusia ni et Heiiothis zea (Ignoffo, 1964).

\section{Les rickettsies.}

Depuis la découverte chez Popillia japonica d'une «blue disease » due à Rickettsiella popilliae (Dutky et Gooden, 1950), une dizaine de cas de rickettsioses ont été décrits chez les insectes de différents ordres: Coléoptères tels que $M$. melolontha ou Tenebrio molitor, Diptères tels que Tipula paludosa, Lépidoptères tels que Hyalophora cecropia, Orthoptères tels que Gryllus bimaculatus ou Schistocerca gregaria. Ces rickettsies ont fait l'objet essentiellement de recherches histopathologiques, à l'exception de $R$. melolonthae, dont le rôle dans les populations de vers blancs et les propriétés épizootiologiques ont été étudiés par Niklas (1960) et nous-même (Hurpin, 1960, 1964). Voisins des bactéries par leur structure, leur métabolisme propre, ces micro-organismes se comportent comme des virus par leur localisation intracellulaire et certains aspects de leur développement (phase d'éclipse, par exemple). De ce fait, il n'est pas possible de les multiplier sur milieu de culture ; d'autre part, leur spécificité, difficile à mettre en évidence avec sûreté, n'a pas fait l'objet de recherches suffisamment poussées pour être bien précisée, en particulier à l'égard des Vertébrés.

Aussi, jusqu'à présent, l'emploi de ce type de germes dans la nature n'a pas été envisagé, malgré les facultés de résistance et les possibilités de transmission d'une génération à l'autre de $R$. melolonthae.

\section{Les protozoaires.}

Ce groupe représente un potentiel important dont l'exploitation suppose encore de nombreuses recherches. Il comprend en effet de multiples catégories : Amibes, Grégarines, Coccidies, Microsporidies, dont de nombreux représentants ont été observés chez des insectes de tous les ordres, surtout pour les Microsporidies (Fig. 4), sans que les relations hôte-parasites soient toujours bien définies: car on trouve tous les intermédiaires entre le commensalisme et le parasitisme strict. Même en ne considérant que les nosémoses, qui sont les maladies à protozoaires de beaucoup les plus fréquentes, les modes d'infection, les processus de la pathogénèse, les conditions de survie et de conservation de la virulence des spores sont encore très mal connues et, par suite, le développement de ces maladies paraît très irrégulier et aléatoire. Souvent présents de façon endémique dans certaines populations d'insectes, on ne sait pas quels facteurs déterminent les épizooties constatées dans la nature ou dans les élevages. 
Par ailleurs, les protozoaires sont difficiles à multiplier, car il faut recourir à l'infection de l'hôte avec tous les aléas que cette opération comporte, faute de milieu de culture artificie!. La sélectivité est aussi mal connue que les autres caractères pathogènes, de sorte qu'il peut être dangereux pour la biocœnose de disperser un agent biotique dont l'action sur les entomophages, par exemple, n'a pas été établie. Or, il y a plusieurs observations de passage de microsporidies d'un insecte à ses parasites, tel Macrocentrus ancylivorus et la Teigne de la pomme de terre.

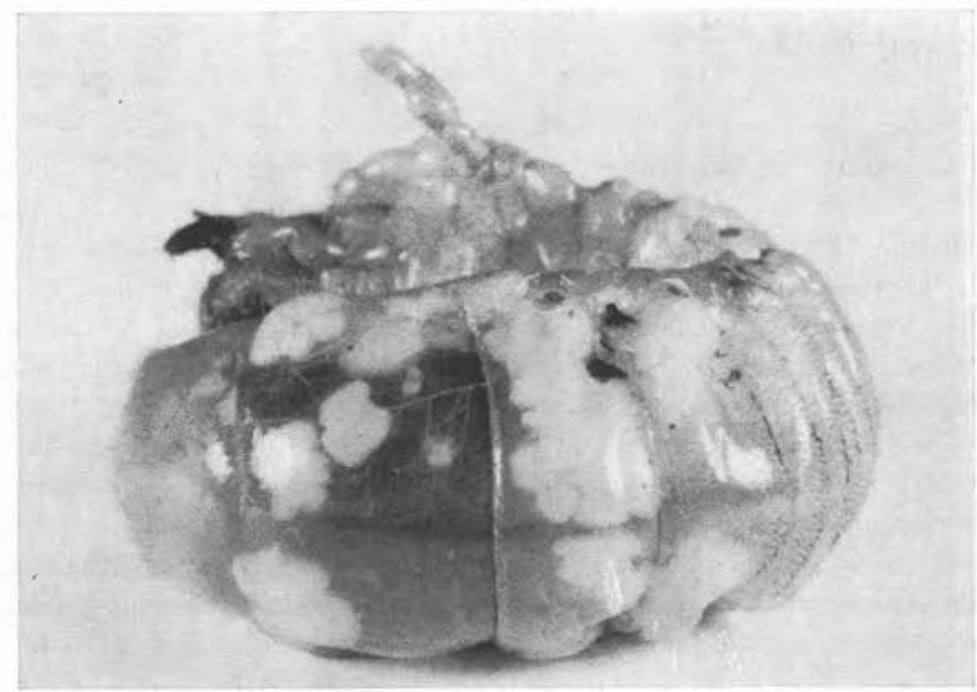

FIG. 4. - Larve du Hanneton commun. Melolontha melolontha L., atteinte de nosémose (taches blanches éparses sous le tégument) $(X 3)$

En dehors des tentatives de Weiser (1957) effectuées avec Thelohania hyphantriae à une échelle très limitée contre des chenilles défoliatrices des arbres fruitiers, et des expériences originales de McLaughlin et al. (1969) de traitement contre l'anthonome du coton à l'aide d'une schizogrégarine incorporée à un attractif chimique, il n'y a pas eu, pour ces diverses raisons, d'essais d'application de protozoaires en lutte biologique, en dépit, répétons-le, de la variété des processus pathologiques dans ce groupe et de son intérêt épizootiologique lié à des phénomènes tels que la transmission intraovulaire, l'infection chronique, et à ses répercussions sur divers caractères physiologiques se traduisant par une réduction de fécondité ou par une sensibilité accrue à d'autres maladies.

\section{Les champignons.}

Les premières expériences, à la fin du siècle dernier, d'emploi de germes entomopathogènes en défense des cultures ont été faites avec des champignons : Beauveria sp., 
Metarrhizium anisopliae, vraisemblablement à cause de l'abondance des mycoses dans les populations d'insectes et de l'aspect caractéristique des individus atteints enrobés dans le mycélium (Fig. 5). Les échecs enregistrés alors et subis également au cours d'expérimentations ultérieures ont abouti à beaucoup de scepticisme sur les possibilités d'utilisation de ces micro-organismes, en dépit de la multiplicité des espèces d'insectes sensibles, de la grande diversité des espèces de champignons en cause et de l'importance et de la fréquence des épizooties naturelles.

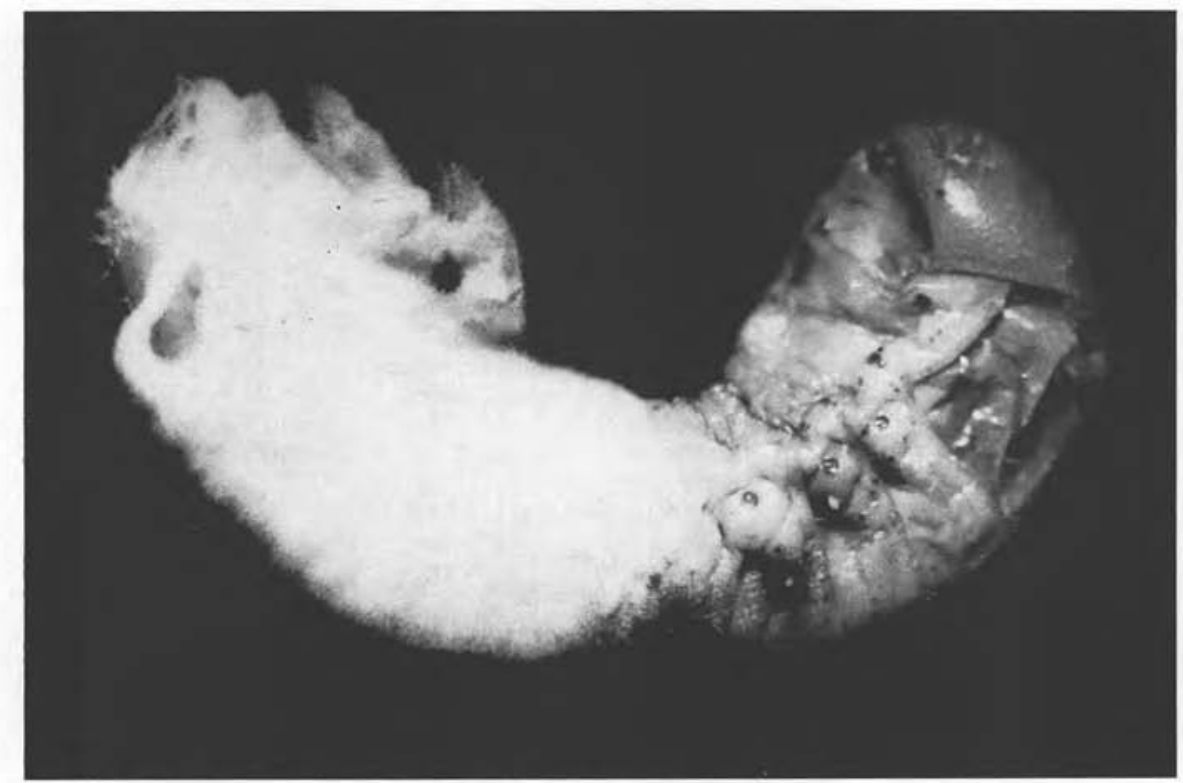

FIG. 5. - Larve du Hanneton commun, Melolontha melolontha L., tuée par la mycose à Beauveria tenella $(\times 3)$

Ces germes sont pourtant facilement cultivables en milieux artificiels, du moins pour tout le groupe des Fungi imperfecti, car la plupart des Entomophthorales posent encore des problèmes à cet égard, en particulier pour obtenir des spores de résistance. Il en est d'ailleurs un peu de même pour les Fungi imperfecti, qui produisent en fermentation des blastospores, sortes de fragments de mycélium enkystés, au lieu des conidiospores émises en fin d'évolution de la maladie chez l'insecte ou en surface de milieux de culture solides.

Les difficultés rencontrées pour l'exploitation des mycoses en lutte biologique sont dues essentiellement au manque de connaissances sur la physiologie et l'écologie des champignons ainsi que sur les facteurs réglant les relations hôte-parasite. Or, beaucoup moins de spécialistes se sont consacrés à l'étude de ce type de maladie qu'aux recherches sur les viroses; cependant, les succès ne sont pas négligeables (tableau 3). Des travaux récents, il ressort que la virulence des différentes souches d'une même espèce 
Tableau 3. - Essais dans la nature d'utilisation avec succès de champignons entomopathogènes (d'après E. Müller-Kögler, 1965)

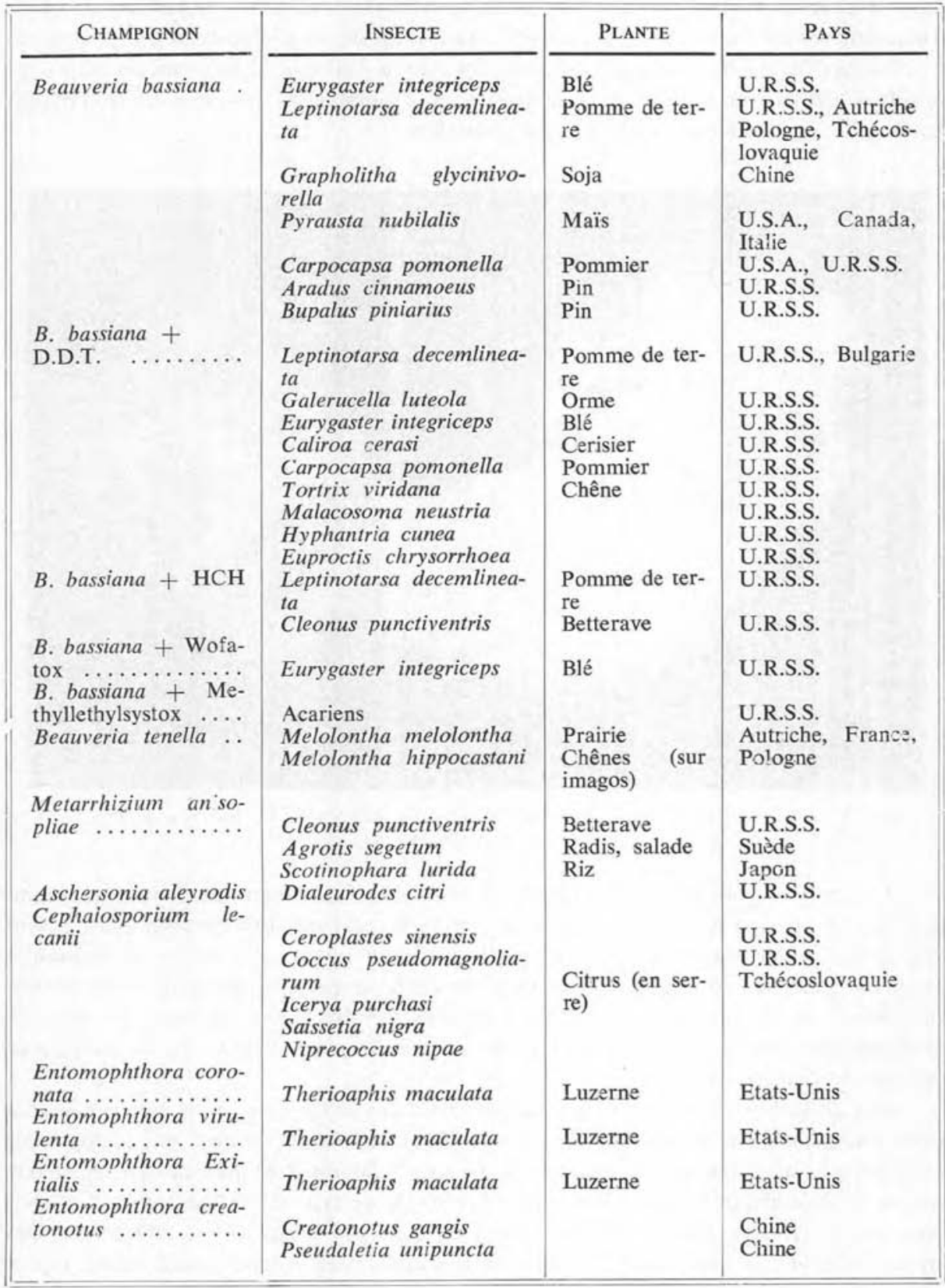


est très variable, et que pour une souche donnée elle est susceptible de changer considérablement avec le temps et selon les conditions de culture (Müller-Kögler, 1965).

Ce degré de virulence de la souche représente le caractère primordial pour la réussite de l'infection; mais, ainsi que Ferron (1967) l'a montré chez $M$. melolontha attaqué par Beauveria tenella, il faut aussi recourir à un nombre minimum de spores, souvent très élevé, et opérer dans une gamme de température voisine de l'optimum thermique de croissance du champignon. En milieu souterrain, l'humidité est toujours suffisante, alors qu'en milieu épigée le rôle exact de ce facteur est encore controversé et reste à préciser.

La spécificité des maladies d'origine cryptogamique est également très mal connue. Elle varie non seulement d'un groupe à l'autre: les Entomophthorales étant réputées plus spécifiques que les Fungi imperfecti, mais aussi d'une espèce à l'autre dans le même genre, puisque Beauveria bassiana a été reconnu pathogène pour 65 espèces d'insectes d'après McLeod (in Heimpel, 1963), alors que $B$. tenella paraît susceptible de se développer seulement chez quelques Melolonthides. On constate même, pour une espèce à gammes d'hôtes très étendues, telle que Metarrhizium anisopliae, une affinité de certaines souches pour un insecte déterminé (Ferron et Diomandé, 1969). Il est donc souhaitable de développer les recherches en ce domaine, à la fois pour employer la souche la plus virulente pour le ravageur visé et pour minimiser les répercussions sur ses parasites ou prédateurs. Le spectre d'activité étendu de beaucoup de champignons, notamment de $B$. bassiana, peut représenter en effet un handicap pour la sauvegarde des insectes antagonistes de l'espèce nuisible que l'on cherche à combattre.

Par contre, l'innocuité à l'égard de Vertébrés paraît la règle générale (MüllerKögler, 1967 ; Schaerffenberg, 1968), les accidents signalés chez quelques manipulateurs de préparations pulvérulentes étant de nature allergique.

\section{DONNEES SUR LA PATHOLOGIE DES INSECTES}

Selon la proposition de Grison (1962), «l'infection épizootique est le résultat d'une balance entre l'agressivité du micro-organisme dispersé massivement et apte à une longue survie dans le temps et dans l'espace, et la réceptivité de l'hôte, compte tenu du comportement, de la constitution génétique et de la variabilité physiologique de celui-ci »; cette balance étant en outre influencée par les conditions du milieu. La réceptivité de l'hôte se manifeste soit au niveau de l'individu, soit au niveau de la population. Elle dépend de la biologie de l'espèce considérée, des phénomènes d'immunité naturelle ou acquise, de l'état physiologique des insectes, de la nature de la population. La biologie intervient dans la réalisation de la coïncidence entre l'hôte et le pathogène. Ainsi, le stade larvaire a une influence déterminante sur l'infection à l'aide de virus, qui est beaucoup plus facile chez les larves jeunes qu'aux stades plus âgés (Stairs, 1965; Tanada, 1967) ; la mue peut constituer une période de moindre réceptivité par élimination des germes avec l'exuvie, dans le cas de champignons dont la voie de pénétration est tégumentaire (Fig. 6), ou par la période de jeûne qui l'accompagne et réduit les quantités de spores bactériennes ou de virus susceptibles d'être 
ingurgités. La diapause nymphale souterraine d'une partie de la génération de Processionnaires du Pin a entraîné la répétition des applications de polyèdres dans le même massif forestier (Grison, Maury, Vago, 1959). Le comportement endophyte des chenilles du-Carpocapse et d'autres Tordeuses les rend difficilement accessibles à l'action de $B$. thurigiensis.

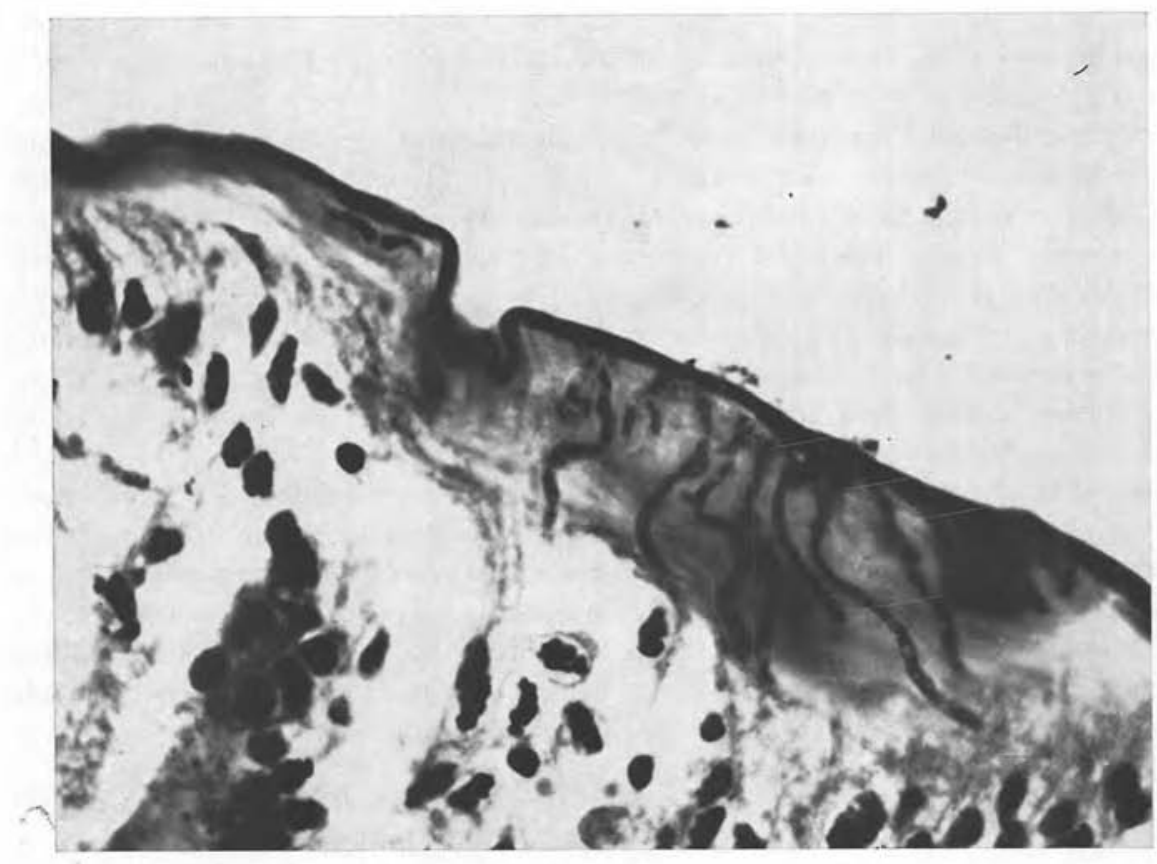

Fıg. 6. - Mycelium de Metarrhizium anisopliae pénétrant dans la cavité générale de Schistocerca gregaria

L'immunité chez les insectes est encore très mal connue. Depuis Metchnikoff, le rôle de la phagocytose a fait l'objet de maintes observations, mais, en dépit de travaux récents, on ne sait pas pourquoi certains germes (bactéries ou virus) sont détruits par les cellules hémocytaires, alors que d'autres ne sont pas ou peu touchés et déterminent la maladie, ni pour quelles raisons dans une même population certains insectes sont atteints par l'infection tandis que d'autres restent indemnes ou guérissent.

Quant à l'immunité humorale par intervention d'anticorps, elle reste encore à démontrer chez les insectes, bien que certains résultats incitent à penser que l'hémolymphe des insectes renfermerait des substances antagonistes des microbes (Heimpel et Harhsbarger, 1965),

Par ailleurs, chez les espèces sensibles à telle ou telle maladie, la possibilité de sélection naturelle ou artificielle de races résistantes paraît variable selon les germes et les espèces d'insectes. Pour les viroses, Martignoni et Schmid (1961) récapitulent quel- 
ques cas de résistance constatés chez des Lépidoptères (Lymantria dispar, Malacosoma disstria, Pieris brassicae), tandis que pour d'autres insectes aucun phénomène de résistance n'a été mis en évidence (Neodiprion sertifer, Malacosoma fragile). Cette différence est peut-être en rapport avec les résultats d'Aizawa et Furuta (1964), qui ont sélectionné en laboratoire une lignée de Bombyx mori résistante aux viroses induites par un choc thermique, mais conservant la même sensibilité à l'infection virale. Par contre, Watanabe (1967) a obtenu par infection orale une réduction de la réceptivité de $B$. mori à la polyédrie cytoplasmique, qui atteint à la cinquième génération un maximum de seize fois la sensibilité des témoins et qui reste stable aux générations suivantes malgré le maintien de la pression de sélection ; ce qui laisse supposer que les facteurs génétiques responsables de la résistance seraient homozygotes.

D'après Yamvrias (1962), il n'y a pas accoutumance de la Teigne de la farine à $B$. thuringiensis après sept générations consécutives. Quant aux mycoses, aucune étude n'a été réalisée à notre connaissance en ce domaine, dont l'importance théorique et pratique pour la lutte microbiologique n'est pourtant pas à souligner. Des différences selon les races d'une même espèce sont signalées chez Malacosoma neustria à l'égard de $B$. thuringiensis (Laux et Franz, 1962), ou chez Bombyx mori à l'égard de Beauveria bassiana (Aoki, 1967).

Au niveau des populations, on connaît maintenant plusieurs exemples démontrant que la réceptivité de l'hôte varie selon l'état de la population: les chenilles de Lymantria dispar présentent un maximum de sensibilité à la polyédrie au moment de la culmination de la gradation et un maximum de résistance l'année suivant l'épizootie (Vasiljevič, 1961) ; d'après Wellington (1962), en cas de rupture d'une gradation de Malacosoma pluviale sous l'effet de conditions climatiques défavorables, ce sont les colonies les plus vigoureuses qui assurent la conservation du virus.

Les chenilles de Phryganidia californica, ravageur du chêne en Californie, prélevées par Martignoni et Schmid (1961) dans une région où l'espèce paraît en équilibre, ont fait preuve d'une résistance plus grande à la virose nucléaire par ingestion libre en laboratoire que les chenilles provenant d'une région où se déclarent des épizooties de temps en temps.

Les chercheurs soviétiques, à la suite des travaux de Lappa (1959) sur les mycoses, attachent une grande importance à l'état physiologique de l'hôte sur la réussite d'une infection.

Le traitement par Beauveria bassiana de trois populations de Malacosoma neustria, dont l'état physiologique est caractérisé par un examen des hémocytes, aboutit à une évolution pathologique différente: la mycose typique ne se manifeste que si la population est saine; lorsque l'aspect des hémocytes est l'indice d'un affaiblissement sans présence de germes, la mortalité est due pour partie à une septicémie, pour partie à la mycose, et aussi à une combinaison des deux types de pathogénèse ; si l'hémolymphe révèle des bactéries ou des levures, une septicémie se déclare très rapidement après l'application du champignon.

Ces résultats, confirmés par d'autres observations, notamment de Telenga, sont exploités en U.R.S.S. dans deux directions : d'une part, l'utilisation simultanée de doses 
réduites d'insecticides et de préparations microbiologiques, à base de Beauveria ou de $B$. thuringiensis, l'insecticide ayant pour but de provoquer une altération de la physiologie de l'hôte, accroissant sa sensibilité au pathogène ; d'autre part, le recours à la prognose qualitative, destinée à prévoir l'évolution de la population d'un ravageur et, par suite, à juger de l'opportunité et de la nature de l'intervention, par examen de l'hémolymphe d'un lot d'insectes prélevé dans cette population. Ces deux méthodes font l'objet d'applications pratiques étendues en U.R.S.S. (Ferron, 1970) et méritent d'être considérées avec beaucoup d'attention. Elles concernent en effet un aspect des relations hôte-pathogène que la plupart des pathologistes ont eu tendance à négliger : le rôle de l'hôte, au profit d'études plus approfondies sur les micro-organismes.

Les processus d'enchaînement de maladies sur lesquels Vago (1956) a attiré l'attention se rapportent à ce domaine de l'influence de l'état physiologique de l'hôte, une première infection non mortelle sensibilisant l'insecte à une infection, ultérieure ou simultanée, et agissant par conséquent comme «cause prédisposante » au sens de Paillot (1933).

L'agressivité du pathogène constitue le deuxième volet du tryptique. Elle est fonction d'un certain nombre de propriétés qui ont été évoquées dans le chapitre précédent pour chacune des catégories d'entomopathogènes: virulence de l'espèce et de la souche, capacité de survie dans le milieu, notamment.

Les différents biotypes de $B$. thuringiensis, identifiés d'après leurs caractères biochimiques, sérologiques ou enzymatiques, se sont révélés présenter une gamme de spécificité différente d'une souche à l'autre, en particulier pour celles qui produisent la toxine thermostable en plus de la toxine des cristaux. Chez les virus, on sait depuis Ossowski (1960) que l'origine géographique des souches d'un même virus peut influer sur la virulence, et quelques auteurs se préoccupent de la variabilité génétique et des interrelations des polyédries cytoplasmiques ou nucléaires (Gershenson, 1956 ; Hukuhara, 1967). Il est parfois possible d'augmenter la virulence d'un virus par passages répétés sur le même hôte (Smirnoff, 1964). Les champignons représentent le groupe de pathogènes où la virulence de la souche est un des principaux facteurs de réussite de l'infection, du fait de la grande variabilité spontanée de cette virulence liée aux échanges de noyaux entre mycéliums, chez les Fungi imperfecti par exemple, et par suite des modifications dans la pathogénie causées par des repiquages successifs sur le même milieu nutritif ou par les modalités de conservation. Cette variabilité peut être mise à profit pour sélectionner des souches plus virulentes ou mieux adaptées à l'insecte considéré par des manipulations physiques (irradiations, ultrasons) ou chimiques (insecticides ou susbstances mutagènes), comme Evlakhova et Chvetzova (1964) l'ont réalisé. Rappelons, en outre (cf. p. 165), que chez une même espèce polyphage telle que Metarrhizium anisopliae, la spécificité varie avec l'insecte hôte à l'origine de la souche utilisée.

Les chances de survie dans le milieu sont en rapport avec les caractéristiques microbiologiques des divers types de germes rappelées précédemment: présence de spores ou non, résistance de ces spores aux agents climatiques, température, dessication, lumière. Nous avons eu récemment (Hurpin, 1966) l'occasion de résumer les 
données sur ce sujet, qui font ressortir les plus grandes facultés de résistance des bactéries sporulées et des virus à corps d'inclusion aux facteurs étudiés et aussi l'intérêt de recherches plus systématiques sur l'influence de l'environnement global, du type de celles entreprises par Grison et collaborateurs sur le maintien de B. thuringiensis dans des forêts traitées contre la Processionnaire du pin ou la Tordeuse du mélèze, ou analogues aux travaux de Jaques (1967) sur la persistance des polyèdres nucléaires de Trichoplusia ni sur les feuilles ou dans le sol. Dans ce domaine, il est évident que le milieu souterrain est plus favorable que le milieu épigé, et est en grande partie responsable du succès rencontré avec $B$. popilliae, par exemple.

Mais, en dehors des modalités de conservation du micro-organisme dans le milieu, il y a lieu de tenir compte également, pour certains germes tels que les virus ou les protozoaires, des possibilités de transmission d'une génération à l'autre, par l'intermédiaire de l'œuf, soit par contamination du chorion consommé par les larves à l'éclosion, qui est de beaucoup le mode le plus fréquent, soit par infection de l'ovaire et de l'embryon, encore mal déterminée dans le cas des viroses.

Par contre, pour ces maladies se pose le problème de la \&latence " dans un individu ou une population correspondant à l'existence pendant un nombre de générations plus ou moins grand, d'une maladie chronique inapparente, qui devient aiguë et provoque une mortalité dans la nature ou dans un élevage sous l'influence des conditions extérieures. Les processus en cause restent à préciser, malgré l'abondance des exemples faisant état de l'intervention de facteurs climatiques (température surtout, hygrométrie, lumière) ou nutritionnels, dans le déclenchement de viroses sans contamination provoquée (Vago, 1964).

Pour les viroses, en particulier, on peut donc faire appel aux deux modes de persistance : conservation des germes dans l'aire géographique considérée et persistance biologique par infection latente ; la détermination du rôle de chacune de ces modalités constitue une des plus importantes questions à résoudre en pathologie des insectes, pour réaliser une opération de lutte microbiologique rationnelle.

Les facteurs du milieu ont une influence prépondérante dans les deux cas, soit en détruisant les virus, soit en assurant le passage de l'infection à un état aigu. Avec les germes autres que les virus, il en est de même, et une abondante littérature (Tanada, 1963 ; Hurpin, 1966) a été consacrée à ce sujet, d'une part en ce qui concerne l'action des différents facteurs climatiques sur la survie et la virulence des micro-organismes, d'autre part en ce qui concerne les répercussions de ces facteurs sur la sensibilité de l'hôte ou leur action sur l'activité des germes. Ces deux aspects entrent dans le concept de «stress * correspondant à l'effet produit sur un organisme par une intervention physiologique ou pathologique. Dans ces phénomènes, il y a à la fois des facteurs activateurs, agissant sur l'agressivité du pathogène, et des facteurs dépresseurs ou prédisposants, intéressant la réceptivité de l'hôte. La plupart de ces facteurs dépendent du milieu (climat, alimentation), et il est souvent difficile de départager leur action sur le germe de leur influence sur l'insecte pour beaucoup de maladies, du fait des relations physiologiques étroites entre les deux antagonistes, en particulier pour les viroses. D'une façon générale, il semble que les agents climatiques agissent surtout sur l'hôte pour les 
maladies à mode de contamination orale (bactérioses, viroses, protozoonoses), et plutôt sur le germe pour les maladies à voie de pénétration tégumentaire (mycoses).

La densité de l'hôte ou et celle du pathogène a été invoquée à plusieurs reprises parmi les causes de «stress», et notamment par Steinhaus (1958). En fait, il faut qu'il y ait surpopulation pour qu'il en soit ainsi, car la densité ne paraît pas être un facteur déterminant dans le développement d'une épizootie, ainsi que l'ont fait ressortir Franz (1961) et Grison (1962). De multiples exemples confirment que le nombre d'insectes ou d'agents infectieux par unité de surface n'est pas une condition essentielle pour le développement et le maintien d'une maladie, c'est seulement un facteur favorisant en augmentant les chances de rencontre, car la distribution spatiale des individus des deux populations importe beaucoup. Il n'en reste pas moins vrai que l'emploi d'une dose minimum de germes est nécessaire pour compenser les pertes dues aux facteurs de destruction, réduire les aléas de la contamination et vaincre la résistance opposée par l'hôte, de sorte que les traitements sont effectués avec des préparations renfermant suffisamment d'éléments pathogènes.

Quant à la densité de l'hôte, elle compte beaucoup moins que la présence d'un stade sensible, l'état physiologique de la population, la phase gradologique de cette population et les autres critères écologiques dont nous allons discuter, sans négliger les impératifs agronomiques.

\section{PRINCIPES ECOLOGIQUES DE LA LUTTE MICROBIOLOGIQUE}

L'objectif recherché en lutte microbiologique est l'introduction dans un écosystème d'un germe pathogène susceptible de se comporter comme un «facteur-clé » de régulation de la population du ravageur, de telle sorte qu'elle se maintienne constamment en dessous du seuil de nuisibilité de celui-ci.

Pour un certain nombre d'insectes, spécialement en milieu forestier, on observe des fluctuations considérables des populations de déprédateurs selon une périodicité parfois bien établie. Ainsi, la Tordeuse du mélèze, Zciraphera griseana $\mathrm{Hb}$, défeuille complètement les mélèzes tous les huit ou neuf ans dans les Alpes d'après les relevés de ces cent dernières années ; Lymantria dispar commet des ravages spectaculaires tous les dix ans environ dans les régions méditérranéennes; Lymantria fumida Butler pullule dans certaines forêts japonaises tous les six ou sept ans.

Dans la plupart des cas, une épizootie virale se manifeste lorsque les niveaux de population atteignent le maximum, et souvent en moins d'une année l'insecte paraît avoir disparu. C'est le début d'une période de «latence», qui est suivie d'une phase de progradation, dont le terme est marqué par la pullulation ou « gradation ».

D'autres insectes forestiers connaissent des fluctuations de populations beaucoup moins régulières, tel Tortrix viridana dans les chênaies de l'Europe occidentale.

Dans les agrocœenoses, les variations des densités de ravageurs par unité de surface sont aussi très importantes, mais sans rythme aussi marqué que pour les défoliateurs forestiers. Cette irrégularité est liée à la biologie de chaque espèce, mais aussi à la 
nature du milieu, beaucoup plus perturbé par l'action de l'homme que le milieu forestier. La périodicité des pullulations pour une même espèce peut dépendre, par exemple, du mode de culture : d'après Remaudière, dans les zones où les céréales sont cultivées sans irrigation, les gradations d'Eurygaster sont caractérisées par une augmentation graduelle de la densité des insectes pendant quelques années et une décroissance souvent brutale. Entre les gradations, des populations de très bas niveau subsistent pendant une période plus ou moins prolongée : dans les zones très arides, où les céréales sont irriguées, on observe des gradations de ce type avec une longue phase de rémission entre deux pullulations, tandis que dans les régions plus tempérées l'irrigation détermine des gradations très rapprochées, et il suffit d'une intervention humaine malencontreuse pour empêcher les processus de fin de gradation.

Chez les espèces migratrices, telles que des Noctuelles, les mouvements de population se font à la fois dans le temps et dans l'espace, ce qui rend plus difficiles les prévisions d'abondance dans un endroit donné.

Le milieu a donc une importance qui ne doit pas être sous-estimée. Ainsi que l'a indiqué Grison (1968), le praticien phytosanitaire a tendance à limiter le problème aux deux éléments : hôte à détruire et agent de destruction, et à négliger le rôle de l'environnement, même lorsqu'il s'agit d'applications microbiologiques. Or, on doit tenir compte du milieu, non seulement à cause de l'influence sur l'évolution des populations du ravageur considéré et sur le comportement des germes utilisés des facteurs climatiques, nutritionnels ou édaphiques, mais aussi du fait des répercussions sur les processus épizootiques de l'environnement global, c'est-à-dire le rôle de l' «écotone » et des stations-refuges d'une part, de l'ensemble de la faune du biotope d'autre part. Il y a lieu également de ne pas négliger le fait que l'apport massif de germes, même s'ils sont déjà présents naturellement en plus faible quantité, correspond à une certaine pollution que l'écologiste préfère limiter le plus possible.

Ces aspects ont été développés par Grison (1970). Nous nous contenterons donc de rappeler quelques exemples déjà cités et qui se rattachent à la notion générale de «lutte intégrée », doctrine fondamentale en matière de protection des plantes. L'écotone se rapporte aux zones de bordure dans l'écosystème envisagé : ce peut être les haies entourant les champs dans les zones de bocage, les «garennes », surfaces boisées conservées dans les grandes plaines découvertes, les lisières de massifs forestiers par rapport aux zones de cultures, etc. Ainsi que Grison et Biliotti l'ont souligné dès 1954 , ces «stations-refuges » servent d'abri à une faune complexe où coexistent des insectes ravageurs, des insectes parasites ou prédateurs de ces ravageurs, ainsi que des insectes dits « indifférents », car il n'ont pas d'action directe sur les végétaux cultivés ; mais ils ne sont pas indifférents au point de vue écologique, par le fait même qu'ils existent, occupent une place et interviennent dans le flux d'énergie de l'écosystème considéré, mais aussi par leur incidence sur la conservation, la dissémination et le développement des ennemis naturels, entomophages et entomopathogènes, des insectes nuisibles. La prise en considération de toute cette faune est un des concepts fondamentaux de la lutte intégrée.

En dehors de leur intervention dans le maintien des micro-organismes par l'inter- 
médiaire d'insectes porteurs, survivants de l'espèce visée ou appartenant à d'autres espèces, les zones marginales peuvent être mises à profit pour procéder à l'introduction du pathogène étudié.

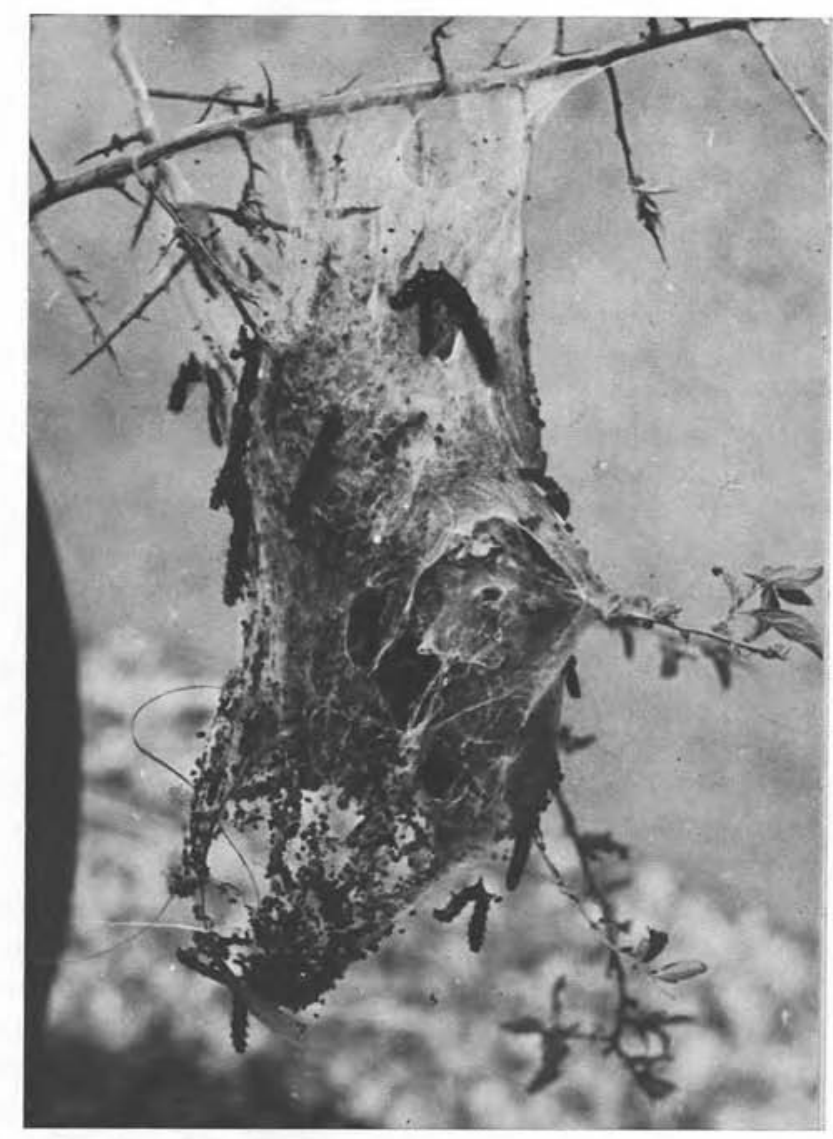

FIG. 7. - Chenilles de Eriogaster lanestris atteintes de virose, pendant à l'extérieur du nid

Ainsi, Karpinski (1950) a tenté de combattre les vers blancs en traitant avec des spores de Beauveria les feuilles des arbres consommées par les hannetons; Evlakhova utilise les déplacements d'Eurygaster integriceps pour créer des foyers d'infection cryptogamique dans les lieux d'hibernation des punaises, dans les bois, en appliquant les spores de Beauveria tenella à la base des gerbes de céréales où se concentrent les insectes au moment de la moisson.

Inversement, les stations-refuges peuvent être des foyers de multiplication du ravageur. En Côte-d'Ivoire, par exemple, les champs de coton sont exposés aux migra- 
tions des Noctuelles, telles que les Heliothis, tandis que les papillons d'Argyroploce déposent leurs œufs sur les maïs non traités où les chenilles prolifèrent. Dans la prévention des infestations, ces stations-refuges ont donc une importance considérable, comme en témoignent les pullulations d'Euproctis chrysorrhoea observées à partir de plantes-hôtes différentes selon les phases de la gradation.

Pour ces différentes raisons, Grison préconise pour la lutte microbiologique la prise en considération d'une agrocœnose aussi délimitée et indépendante que possible, et par conséquent des opérations sur des superficies assez étendues, à l'exclusion des applications parcellaires dont la signification écologique est aléatoire.

Mais de telles opérations couvrant des surfaces importantes suscitent, dans le cas le plus fréquemment envisagé de dispersion massive du germe, des risques de pollution du milieu par ce fait même. C'est pourquoi, parallèlement à l'intérêt économique et pratique de la réduction de la quantité de préparation à produire et à épandre, il est souhaitable de localiser les applications, soit par intervention dans les stations-refuges, soit par exploitation de certains caractères éthologiques de l'hôte ou de propriétés pathologiques du pathogène.

Diverses expériences ont été réalisées dans cette voie : pulvérisation de polyèdres de Neodiprion hercyniae ou de $N$. sertifer sur quelques arbres en forêts de conifères au Canada, où la maladie n'existait pas et où elle s'est établie, répandue très rapidement et maintenue au point de contrôler efficacement ces Tenthrèdes (Bird et Burk, 1961) ; distribution de cocons de Neodiprion swainei provenant de larves infectées par une dose subléthale de virus de façon que les adultes assurent la dispersion de la maladie dans tout le massif forestier (Smirnoff, 1962) ; lâchers dans les champs de luzerne de papillons femelles de Colias eurytheme, dont les génitalia ont été badigeonnés avec une pâte contenant des virus (Martignoni et Milstead, 1962) ; mise en place, dans les luzernières attaquées par les pucerons Therioaphis maculata Buckton, de petites boîtes de carton renfermant des cultures d'Entomophthorales en cours de sporulation (Hall et Dunn, 1958). Dans cette optique écologique, l'intérêt est porté essentiellement à l'action durable du traitement microbiologique, même si ses premiers effets ne s'observent qu'après quelque temps. Le critère d'appréciation des résultats n'est pas, alors, le taux de mortalité immédiat, mais l'indice de morbidité obtenu et l'installation du pathogène dans la biocœnose considérée. Celles-ci sont liées au maintien d'un minimum de ravageurs pour la conservation du germe et à la persistance des conditions écologiques.

Les massifs forestiers constituent les milieux les plus favorables, par leur étendue, la permanence de la végétation, la stabilité de la faune; les prairies permanentes peuvent leur être comparées dans une certaine mesure, ainsi que les vergers ; par contre, les cultures annuelles, par le renouvellement des assolements, la répartition des différentes cultures selon cet assolement, les dimensions souvent réduites des parcelles affectées à telle ou telle production, posent le problème du maintien d'une maladie à l'état endémique et des possibilités de manifestations épizootiques. Dans ce contexte écologique, les phénomènes épizootiologiques sont particulièrement difficiles à expliquer. Ainsi que le constate Rivers (1966), par exemple, on ne sait pas comment la 
granulose de la Piéride du chou (Fig. 8), s'est maintenue entre les années trente et les années cinquante, correspondant à deux périodes où elle a été observée dans la quasitotalité des populations, alors que dans l'intervalle, et depuis ces dix dernières années, les chenilles de cette espèce paraissent en être exemptes.

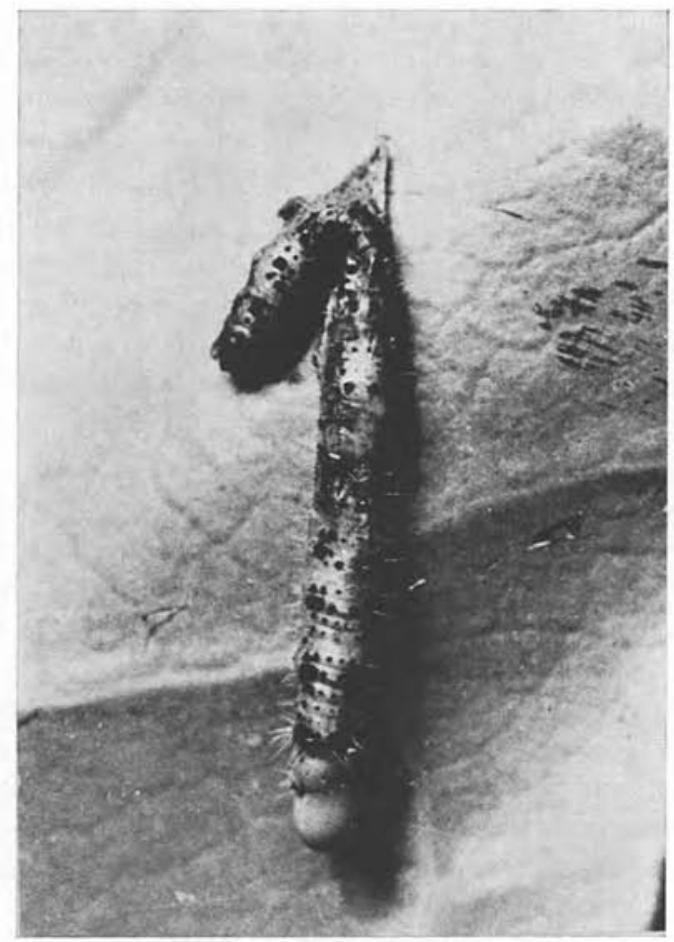

FIG. 8. - Chenille de Pieris brassicae morte de granulose libérant les virus dans le liquide de décomposition

Le rôle du milieu se traduit aussi par la facilité avec laquelle un pathogène peut être introduit dans un écosystème suivant son origine, de la même façon que pour un insecte entomophage. Les exemples de grand succès en lutte biologique, tels que le contrôle de la cochenille Icerya purchasi en Californie par Rodolia cardinalis, coccinelle importée d'Australie, se rapportent généralement à l'implantation d'un parasite originaire d'une autre région.

Il en est de même en lutte microbiologique ; le cas le plus spectaculaire est celui de la myxomatose chez les vertébrés. Chez les insectes, les principales réussites ont été enregistrées à l'aide de germes importés, soit involontairement, comme le virus nucléaire de $N$. hercyniae au Canada amené accidentellement d'Europe à l'occasion d'expéditions de parasites entomophages, soit volontairement, comme le virus nucléaire de $N$. sertifer 
importé de Suède. Dans les deux cas, une seule introduction de quantités limitées de matière infectieuse a suffi pour déclencher rapidement une épizootie dont les effets sont prolongés par la réalisation d'un état endémique (Bird, 1962).

Avec les mycoses, en dehors des résultats obtenus par Laird et Colless (1962) dans la lutte contre Aedes polynesiensis Marks aux îles Tokelau par l'introduction de Coelomomyces stegomyiae Keilin depuis Singapour, nous citerons l'exemple des Aschersonia, Fungi imperfecti, de Floride ou de Chine, utilisés avec succès au Caucase pour combattre l'Aleurode du citronnier originaire de l'Asie du sud-est.

Dans son aire d'origine, aux Etats-Unis, Hyphantria cunea Drury ne semble pas sujet à autant de maladies qu'en Europe. Celles-ci, issues d'autres insectes européens, se sont donc naturellement adaptées à l'espèce introduite et contribuent à la limitation de ses dégâts.

\section{CRITERES AGRONOMIQUES}

Les besoins du praticien et les conditions de l'économiste en matière de protection phytosanitaire varient selon la catégorie de culture et le mode de commercialisation des produits.

Il est évident que les résultats et, par suite, les procédés utilisés peuvent être différents en forêt, où la production se calcule sur une longue période, et en culture intensive, dont la productivité doit être la plus grande possible. Par ailleurs, une économie libérale où la concurrence est sévère a des exigences dans la qualité des produits que ne connaît pas toujours une économie dirigée, qui peut imposer certaines normes, en fonction des possibilités de la technique. C'est ainsi que la propagande en faveur de fruits indemnes de tout défaut aboutit à des taux d'efficacité des pesticides très élevés qui supposent une mortalité quasi totale dans les plus brefs délais, ce qui est en contradiction avec les préoccupations de l'écologiste et les possibilités du pathologiste. Pour le technicien phytosanitaire, le principe est de maintenir le niveau de population du déprédateur au-dessous du seuil de tolérance économique défini par la densité des ravageurs à partir de laquelle il y a lieu de procéder à des traitements pour éviter d'atteindre des dommages ayant une répercussion économique (niveau de dégâts économiques). Ce seuil de tolérance dépend en premier lieu de la nature de la culture : il est, pour un même ravageur, d’autant plus élevé que la densité du végétal par unité de surface est plus grande ( 25 vers blancs au mètre carré en prairie contre 3 ou 4 en pépinière, par exemple), mais il est aussi fonction de la valeur de la récolte; il est d'autant plus bas que la production est plus chère.

L'exemple de Heliothis zea en Californie, cité par Stern (1966) illustre cette variabilité. Cette noctuelle s'attaque à différentes cultures, luzerne, coton, maïs, situées dans les champs voisins. Sur luzerne, elle n'atteirt jamais des densités suffisantes pour craindre des dégâts économiquement sensibles; sur coton, le seuil de tolérance est de 4 larves pour 100 plantes, de sorte que beaucoup de champs doivent être traités plusieurs fois au cours de la saison, tandis que sur maïs, vendu pour la consommation 
humaine, les épis devant être indemnes de toute attaque, le seuil économique est voisin de zéro, et de très nombreux traitements sont nécessaires.

Les seuils de tolérance sont également fonction de la région considérée, de son climat en général et pendant telle saison, car il influe à la fois sur le comportement du ravageur et sur la résistance de la plante, des pratiques culturales, etc.

C'est la prise en considération de cette notion de seuil de tolérance au lieu de la recherche, illusoire et dangereuse, de l'élimination de l'espèce nuisible, qui constitue un des principes fondamentaux de la lutte intégrée, que Smith et Reynolds (1966) définissent schématiquement ainsi : « Integrated pest control is a pest population management system that utilizes all suitable techniques in a compatible manner to reduce pest populations and maintain them at levels below those causing economic injury. »

Cette conception apparaît de plus en plus indispensable en protection des plantes, et fait appel notamment à la combinaison rationnelle des méthodes de lutte biologique et chimique, de façon à bénéficier au maximum de l'action des ennemis naturels présents dans la culture ou volontairement introduits, et à apporter le minimum de perturbations aux équilibres biocœnotiques au sens de Schwenke (1953), en profitant le plus possible des avantages de chacune des méthodes et en limitant les conséquences de leurs inconvénients, tout en tenant compte des exigences économiques et des normes de qualité imposées pour la commercialisation de la récolte.

La sélectivité de la lutte biologique, et en particulier de l'arme microbiologique, représente souvent un inconvénient en protection des cultures, car le praticien a généralement à combattre plusieurs ennemis dans la même culture : Piérides et Noctuelles dans les champs de choux, Tordeuses et défoliatrices diverses dans les vergers, etc.

Or, des préparations microbiologiques ne sont pas disponibles pour chacun de ces cas. Il y a donc lieu d'employer des procédés de complément, autre moyen biologique tel que des parasites ou produit chimique. De même, la recherche de rendements de plus en plus élevés, et d'une efficacité de plus en plus grande des mesures phytosanitaires, paraît en contradiction, pour un certain nombre de productions (fruits, fleurs), avec la survie d'une quantité suffisante d'insectes pour satisfaire l'épizootiologiste, afin d'assurer la conservation du germe, et l'écologiste, pour éviter de créer une «place vide» susceptible d'être occupée par une espèce beaucoup plus dangereuse.

Par ailleurs, le morcellement des parcelles, la diversité des cultures dans une zone déterminée et leur variabilité dans le temps en fonction des rotations en usage, la rapidité de la récolte dans le cas des cultures annuelles qui ne laissent que de brefs délais entre le traitement et l'effet sur la population de déprédateurs, ne permettent pas, dans l'état actuel de nos connaissances tout au moins, d'envisager dans les champs cultivés le recours à la lutte microbiologique à long terme telle que nous l'avons présentée dans les paragraphes précédents. On doit se contenter d'utiliser certaines préparations de pathogènes en tant qu'insecticides sélectifs, telles les formules à base de B. thuringiensis actives contre divers Lépidoptères (cf. tableau I) ou celles à base de polyèdres nucléaires en cours de fabrication industrielle aux Etats-Unis pour la lutte contre les Noctuelles du coton, du maïs ou du tabac. Bien que le mode d'action de ces deux catégories de germes soit différent, le mode d'emploi en agriculture est analogue: appli- 
cation localisée pour prévenir les dégâts chaque fois que les niveaux de populations le justifient, à des doses suffisantes et à une époque convenable. C'est ainsi que pour protéger les champs de coton ou de maïs contre Heliothis, des préparations à base de polyèdres nucléaires sont épandues dans différentes régions des Etats-Unis (Mississipi, Texas), de la même façon que des insecticides, en adaptant les doses à l'âge des insectes, le nombre de traitements à l'évolution des populations et au seuil de tolérance de la culture.

Les meilleures conditions d'infection étant réalisées par l'ingestion du chorion de l'œuf contaminé par la chenille à l'éciosion et les virus se conservant mal sur les plantes, à cause en particulier de l'action destructrice des ultraviolets, on est amené à faire des applications répétées à quelques semaines d'intervalle, pendant toute la période de ponte des papillons, pour parvenir à une protection analogue à celle obtenue avec les insecticides chimiques (Ignoffo, Chapman et Martin, 1965; Allen et Brazzel, 1966).

Par contre, en forêt, il est possible d'envisager une intervention à plus long terme en opérant au moment opportun dans la gradation. C'est ainsi que les collègues japonais ont obtenu des résultats significatifs en traitant des pinèdes par pulvérisation de polyèdres nucléaires lorsque la population de Dendrolimus spectabilis Butler est en remontée, mais avant qu'elle atteigne le maximum de densité. Les applications sont faites lorsque les larves sont au $7^{\circ}$ stade, bien que la sensibilité des chenilles soit plus élevée aux $2^{\circ}$ et $3^{\circ}$ stades, afin de tenir compte de l'importante mortalité ( $80 \%$ environ) due à différents antagonistes qui affecte le début de la vie larvaire (Katagiri, 1969). Dans le même esprit, le groupe de travail franco-suisse sur la Tordeuse du Mélèze, un des rares insectes dont la dynamique des populations est bien connue, a procédé en 1967, grâce au concours de la D.G.R.S.T., au traitement de 2.700 ha de mélezins dans la vallée de la Clarée, près de Briançon, avec $B$. thuringiensis, en période d'intergradation, en vue d'atteindre la population résiduelle et retarder sinon supprimer la gradation suivante. Les premiers résultats après deux ans sont très encourageants, car la remontée des populations est très nettement plus lente dans la vallée traitée que dans les vallées voisines.

Les vergers et les prairies permanentes, par leur longévité, la complexité de leur faune, représentent des cas intermédiaires. Lorsqu'il s'agit d'insectes souterrains, tels que les vers blancs, des effets à long terme peuvent être espérés, grâce à la conservation des germes dans le sol selon le processus démontré avec $B$. popilliae : les larves du Hanneton japonais malades forment des foyers secondaires d'infection qui assurent la multiplication et la dispersion du pathogène. Chez le Hanneton commun, en France, notre laboratoire étudie, grâce à l'appui de la D.G.R.S.T., les possibilités d'utilisation de la mycose à Beauveria tenella selon des modalités analogues.

\section{CONCLUSIONS}

Au terme de cet exposé, il apparaît que les bases microbiologiques (inventaire des germes entomopathogènes, définition de leurs propriétés) et les exigences agronomiques sont, dans les principes de la lutte microbiologique, les deux données les mieux établies. 
Pour une utilisation méthodique de l'arme microbiologique comme facteur préventif des pullulations de ravageurs, il reste beaucoup de questions à résoudre dans les deux autres domaines: pathologie et écologie. En pathologie, les spécialistes étudiant les invertébrés, comme leurs collègues médecins ou vétérinaires, ne savent pas, lorsqu'une maladie se déclare chez un individu ou une épizootie dans une population, quels rôles respectifs jouent l'état physiologique de l'hôte et l'agressivité du germe en fonction des conditions du milieu. Il semble que l'attention ait davantage été portée jusqu'à présent aux facteurs dépendant du pathogène et que la réceptivité de l'hôte ait été négligée, aussi bien en médecine qu'en pathologie des insectes. Le manque d'informations de cet ordre est particulièrement sensible au niveau des populations. Or, si l'on considère, avec Grison (1969) et la plupart des auteurs, que la lutte biologique est un des aspects de l'écologie appliquée, il est indispensable de connaître l'état physiologique et gradologique d'une population, son potentiel de réceptivité au micro-organisme, les modalités d'intégration de celui-ci dans le cortège d'ennemis naturels et d'autres agents de régulation, pour pouvoir interpréter les résultats obtenus et mettre à profit rationnellement les possibilités de succès. Ces études de biocœnotique et de déterminisme des fluctuations naturelles des populations exigent une infrastructure importante et des moyens en personnel considérables à mettre en œuvre pendant plusieurs années. Il n'est donc pas étonnant que les recherches en ce domaine soient peu avancées, sauf lorsque les efforts nécessaires sont consentis, à l'image de nos collègues suisses qui ont pu poursuivre depuis plus de dix ans un tel travail sur la Tordeuse du Mélèze, ou à l'exemple des investigations sur la Processionnaire du Pin conduites en France par l'I.N.R.A. avec le soutien de la D.G.R.S.T.

De telles études sont encore plus complexes en milieu cultivé, à cause de l'intervention continuelle de l'homme, alors qu'en forêt c'est le climat, lequel est d'ailleurs dans la plupart sinon dans la totalité des cas le «facteur-clé », qui est à l'origine des modifications des phénomènes gradologiques.

Dans les agrocœnoses, du fait des assolements et des rotations culturales, de la recherche d'un haut rendement et d'une très grande qualité de la récolte, actuellement la lutte microbiologique doit être utilisée comme un des éléments d'un programme de lutte intégrée pour lequel les germes entomopathogènes présentent le grand avantage de la spécificité, de l'innocuité à l'égard des insectes entomophages, de l'absence de résidus et de risque de pollution des chaînes trophiques. Dans cette optique, les critères de mortalité ont alors un rôle prédominant, mais les effets différés des micro-organismes ne sont pas négligés. Comme l'a souligné Biliotti (1966), cette conception de « lutte intégrée » ne doit pas être considérée comme un aveu d'impuissance de la lutte biologique. Au contraire, elle traduit le souci des spécialistes de tenir compte des principes de l'écologie générale et de toujours veiller à situer leur action, à court ou à moyen terme, en fonction de la dynamique des populations, en limitant les répercussions sur l'environnement.

Mais l'application de cette doctrine suppose une éducation des praticiens à la fois pour les objectifs et pour les modalités des traitements phytosanitaires. Question qu'il n'est pas de notre propos de traiter ici. 


\section{Bibliographie}

Aizawa (K.) et Furata (Y.), 1964. - Resistance to polyhedroses in $\mathrm{F}_{1}$ hybrids between resistant and original strains in the silkworm Bombyx mori. J. Sericult. Sci. Japan, 33 : 403-406.

Allen (G. E.), Gregory (B. G.) et Brazzel (J. R.), 1966. - Integration of the Heliothis nuclear polyhedrosis virus into a biological control program on cotton. J. econ. Ent., 59: 1333-1336.

AoKI (K.), 1967. - Relation between the species of insects and the pathogenicity of muscardines. Proceed. Joint U.S.-Japan Seminar Microbial Control, Fukuoka: 115118.

Biliotri (E.), 1966. - Les limites des méthodes traditionnelles de lutte biologique. Proceed. FAO Symposium on Integrated Pest Control, $1:$ 63-73.

BIRD (F. T.), 1964. - The use of virus in biological control. Entomophaga, Mém. Hors Série $\mathrm{n}^{\circ} 2$ : $465-473$.

BIRD (F. T.) et BURK (J. M.), 1961. - Artificially disseminated virus as a factor controlling the European Spruce sawfly Diprion hercyniae $(\mathrm{Htg})$ in the absence of introduced parasites. Can. Entom., $93: 228-238$.

Bucher (G. E.), 1960. - Potential bacterial pathogens of insects and their characteristics. J. Insect Pathology, 2: 172-195.

Cameron (J. W. Mac Bain), 1966. - Suitability of pathogens for biological control. In «Insect Pathology and Microbial Control». Proceed. Intern. Coll. Wageningen. North Holland Publish. Co. : 182-196.

DutKy (S. R.) et Gooden (E. L.), 1950. - Coxiella popilliae, n. sp., a rickettsia causing blue disease of Japanese Beetle larvae. J. Bacteriol., 63: 743-750.

Evlakhova (A. A.) et Chvetsova (O. I.), 1964. - Méthodes de sélection des formes pathogènes de microorganismes. Entomophaga, Mém. Hors-Série $\mathrm{n}^{\circ} 2$ : 521-529.

FERRON (P.), 1967. - Etude en laboratoire des conditions écologiques favorisant le développement de la mycose à Beauveria tenella du ver blanc. Entomophaga, 12: 257-293.

—, 1970. - Orientation des recherches effectuées en U.R.S.S. sur les champignons entomopathogènes. Ann. Zool. Ecol. animale, numéro hors série, 3, 117-134.

— et Diomandé (T.), 1969. - Sur la spécificité à l'égard des insectes de Metarrhizium anisopliae (Metsch) Sorokin (Fungi imperfecti) en fonction de l'origine des souches de ce champignon. C.R. Acad. Sci. Paris, 268: 331-332.

FranZ (J. M.), 1961. - Biologische Schädlingsbekämpfung, in Handbuch der Pflanzenkrankheiten, $6^{\circ}$ éd. Paul-Parey, Berlin : 1-302.

Gershenson (S. M.), 1956. - Le mécanisme de l'infection des cellules par le virus polyédrique à la lumière des observations sur les dimensions et la forme des polyèdres. Dokl. Akad. Nauk SSSR, 110: 1199-1201 (en russe).

Grison (P.), 1962. - Réflexions sur l'épizootiologie. Entomophaga, Mém. Hors-Série $n^{\circ}$ L : 483-506.

—, 1970. — Lutte biologique et écologie appliquée. Bull. Soc. Ecologie, 1, 7-18. 
— et Biliotri (E.), 1954. - Le rôle des stations-refuges dans la conservation et la dispersion des insectes phytophages et entomophages. C.R. Congrès Protection Nature, Copenhague : 137-144.

-, Maury (R.) et Vigo (C.), 1959. - La lutte contre la Processionnaire du pin Thaumetopoea pityocampa Schiff. dans le massif du Ventoux. Essais d'utilisation pratique d'un virus spécifique. Revue Forest. franç., $5:$ 353-370.

Hall (I. M.) et DunN (P. H.), 1957. - Entomophthorous fungi parasitic on the spotted alfalfa aphid. Hilgardia, $27:$ 159-181.

Heimpel (A. M.), 1965. - Microbial control of insects. World Rev. Pest Control, 4: 150161.

- et Harshbarger (J. C.), 1965. - Symposium on microbial insecticides. V. Immunity in insects. Bacteriol. Rev., 29: 397-403.

Hukuhara (T.), 1967. - Genetic variation of polyhedrosis viruses of insects. Proceed. Joint U. S.-Japan Seminar Microbial Control, Fukuoka: 7-11.

HURPIN (B.), 1960. - Observations pathologiques sur les maladies à rickettsies des larves de Scarabaeidae. C.R. $11^{\mathrm{e}}$ Congrès Intern. Entomologie, Vienne, 2 : 875-880.

—, 1964. - Influence de certains facteurs du milieu sur la virulence de Rickettsiella melolonthae Krieg. C.R. 12 ${ }^{\mathrm{C}}$ Congrès Intern. Entomologie, Londres : 727.

-, 1966. - Influence des facteurs du milieu in «Insect Pathology and Microbial control . Proceed. Intern. Coll. Wageningen. North Holland Publish, Co., Amsterdam : 135161.

—, 1966. - Possibilités d'utilisation des microorganismes entomopathogènes dans la lutte intégrée. Proceed. FAO Symp. Integrated Pest Control, Rome, '2 : 149-165.

IGNOFFo (C. M.), 1964. - Production and virulence of a nuclear polyhedrosis virus from Trichoplusia ni (Hübner) reared on a semisynthetic diet. J. Insect Pathology, 6: 318-326.

-, Chapman (A. J.) et Martin (D. F.), 1965. - The nuclear-polyhedrosis virus of Heliothis zea (Boddie) and Heliothis virescens (Fabricius). III. Effectiveness of the virus against field populations of Heliothis on cotton, corn and grain sorghum. J. Invertebrate Pathology, 7: 227-235.

- et Hermpel (A. M.), 1965. - The nuclear-polyhedrosis virus of Heliothis zea (Boddie) and Heliothis virescens (Fabricius). V. Toxicity-pathogenicity of virus to white mice and guinea pigs. J. Invertebrate Pathology, $7: 329-340$.

JAQUES (R. P.), 1967. - The persistence of a nuclear polyhedrosis virus in the habitat of the host insect Trichoplusia ni. I. Polyhedra deposited on foliage. II. Polyhedra in soil. Can. Entom., 99: 785-794, 820-829.

KARPINSKI (J. J.), 1950. - Problème de la lutte contre le Hanneton au moyen du champignon Beauveria densa Pic. Ann. Univ. Marie Curie-Sklodowska, 4: 29-67 (en polonais).

KATAGIRI (K.), 1969. - Review on microbial control of insect pests in forests in Japan. Entomophaga, 14 : 203-214.

LAIRD (M.) et Colless (D. H.), 1962. - A field experiment with a fungal pathogen of mosquitoes in the Tokelau islands. Proceed. Intern. Congr. Entomology, Vienne, $1960,2: 867-868$. 
LAPPA (N.-V.), 1959. - Influence du champignon Beauveria bassiana sur la pathogénèse des chenilles de Malacosoma neustria en présence d'un état latent d'infection. Naucn. Trudy Ukrain. Akad. Selsk. Nauk, VIII : 234-240 (en russe).

LAUX (W.) et Franz (J. M.), 1962. - Úber das Auftreten von Individualunterscheiden beim Ringelspinner Malacosoma neustria L. Z. angew. Ent., 50: 105-110.

Laughlin (R. E.), Cleveland (T. C.), Daum (R. J.) et Bell (M. R.), 1969. - Development of the bait principle for boll weevil control. IV. Field tests with a bait containing a feeding stimulant and the sporozoans Glugea gasti and Mattesia grandis. J. Invertebrate Pathology, 13: 429-441.

Martignoni (M. E.) et SCHMid (P.), 1961. - Studies on the resistance to virus infections in natural populations of Lepidoptera. J. Insect Pathology, 3: 62-74.

- et Milstead (J.E.), 1962. - Transovum transmission of the nuclear polyhedrosis virus of Colias eurytheme Boisduval through contamination of the female genitalia. $J$. Insect Pathology, 4: 113-121.

Müller-Kögler (E.), 1965. - Pilzkrankheiten bei Insekten. Paul Parey, Belin, 444 p.

-, 1967. - Nebenwirkungen insektenpathogener Pilze auf Mensch und Wirbeltiere: aktuelle Fragen. Entomophaga, 12: 429-441.

NIKLAS (O.F.), 1960. - Standorteinflüsse und natürliche Feinde als Begranzungsfaktoren von Melolontha-Larvenpopulationen eines Waldgebietes (Forstamt Lorsch, Hessen) (Coleoptera, Scarabaeidae). Mitt. Biol. Bund. Land- u. Forstwiss, Berlin, 101: 1-60.

OssowsKY (L. L. J.), 1960. - Variation in virulence of wattle bagworm virus. J. Insec! Pathology, 2: 35-43.

Paillot (A.), 1933. - L'infection chez les insectes. G. Patissie;, Trévoux, 535 p.

PAsteur (L.), 1874. - Sur l'utilisation des champignons pour combattre le Phylloxera. C.R. Acad. Sci., Paris, 79 : 1233-1234.

Rivers (C. F.), 1966. - The natural and artificial dispersion of pathogens in \& Insect Pathology and Microbial control ». Proceed. Intern. Coll. Wageningen. North Holland Publ., Co. : 252-263.

SCHAERfFenberg (B.), 1968, - Untersuchungen über die Wirkung der insektentötenden Pilze Beauveria bassiana (Bals) Vuill. und Metarrhizium anisopliae (Metsch.) Sorok. auf Warmblütter. Entomophaga, 13: 175-182.

Smirnoff (W. A.), 1962. - Trans-ovum transmission of virus of Neodiprion swainei Midd. (Hymenoptera, Tenthredinidae). J. Insect Pathology, 4: 192-200.

—, 1964. - La lutte aux insectes nuisibles à l'aide de virose. Ann. Soc. Entomol., Québec, 9: 43-53.

SMith (R. F.) et ReYnolds (H. T.), 1966. - Principles, definitions and scope of integrated pest control. Proceed. FAO Syimposium Integrated Pest Control, 1: 11-17.

StaIRS (G. R.), 1965. - Quantitative differences in susceptibility to nuclear-polyhedrosis virus among larval instars of the forest tent caterpillar, Malacosoma disstria (Hübner). J. Invertebrate Pathology, $7:$ 427-429.

Steinhauss (E. A.), 1946. - Insect microbiology. Comstock Publ., Co., lthaca, N-Y, 763 p.

-, 1949. - Principles of insect pathology. Mac Graw Hill Books Co., New-York, 757 p.

- 1958. - Crowding as a possible stress factor in insect disease. Ecology, 39: 503-514. 
STERN (V. M.), 1966. - Significance of the economic threshold in integrated pest control. Proceed. FAO Symposium Integrated Pest Control, 2: 41-56.

TANADA (Y.), 1961. - Bacterial control of insect pests. J. Agric. Veter. Chem., 114-116, 157-159.

-, 1963. - Epizootiology of infectious diseases in « Insect Pathology, an advanced treatise \$, 2 (Ed. E. A. Steinhaus). Academic Press, New York: 423-475.

-, 1967. - The role of viruses in the regulation of the population of the armyworm Pseudaletia unipuncta (Haworth). Proceed. Joint U-S-Japan Seminar Microbial Control, Fukuoka : 25-31.

VAsiljević (L.), 1961. - Susceptibilité des chenilles de Bombyx disparate (Lymantria dispar L.) envers la polyédrie dans les diverses phases de gradation de leur développement dans la nature. Entomophaga, $6: 269-276$.

VAGo (C.), 1956. - L'enchaînement des maladies chez les insectes. Thèse Doctorat Sciences Naturelles, Faculté Aix-Marseille, Saint-Amand, Bussière, 184 p.

—, 1964. - Sur la potentialité des germes entomopathogènes en lutte microbiologique. Rev. Pathol. vég. Entom. agric., 43 : 101-111.

—, 1964. - Ecologie des viroses d'insectes. Entomophaga, Mém. Hors-Série $n^{\circ} 2$ : 423-443.

Watanabe (H.), 1967. - Development of resistance in the silkworm Bombyx mori to peroral infection of a cytoplasmic polyhedrosis virus. J. Invertebrate Pathology, 9: 474-479.

WeISER (J.), 1957. - The possibilities of biological struggle with Hyphantria cunea Drury. Czech. Parasitol., 4 : 359-367.

-, 1962. - Biological insect control. Adv. Biol. Sci., 123-133.

Wellington (W.G.), 1962. - Population quality and the maintenance of nuclear polyhedrosis between outbreaks of Malacosoma pluviale Dyar. J. Insect Pathology, 4: 285-305.

YAMVRIas (C.), 1962. - Contribution à l'étude du mode d'action de Bacillus thuringiensis Berliner vis-à-vis de la Teigne de la farine Anagasta (Ephestia) kühniella Zeller (Lepidoptera). Entomophaga, 7 : 101-159. 